OPEN ACCESS

Edited by:

Alastair Martin Mitri Baylis,

South Atlantic Environmental Research Institute, Falkland Islands

Reviewed by:

Stella Villegas-Amtmann, University of California, Santa Cruz,

United States

Mia Wege,

University of Pretoria, South Africa

Theoni Photopoulou,

University of St Andrews,

United Kingdom

*Correspondence:

Giulia Roncon

giulia.roncon@utas.edu.au

Specialty section:

This article was submitted to

Marine Megafauna,

a section of the journal

Frontiers in Marine Science

Received: 04 June 2018 Accepted: 19 November 2018

Published: 14 December 2018

Citation:

Roncon G, Bestley S, McMahon CR, Wienecke $B$ and Hindell MA (2018)

View From Below: Inferring Behavior and Physiology of Southern Ocean

Marine Predators From Dive Telemetry. Front. Mar. Sci. 5:464. doi: 10.3389/fmars.2018.00464

\section{View From Below: Inferring Behavior and Physiology of Southern Ocean Marine Predators From Dive Telemetry}

\author{
Giulia Roncon $^{1 *}$, Sophie Bestley 1,2,3,4, Clive R. McMahon ${ }^{1,2,3}$, Barbara Wienecke ${ }^{2}$ and \\ Mark A. Hindell $1,2,3,4$ \\ ${ }^{1}$ Institute for Marine and Antarctic Studies, University of Tasmania, Hobart, TAS, Australia, ${ }^{2}$ Australian Antarctic Division, \\ Department of the Environment and Energy, Kingston, TAS, Australia, ${ }^{3}$ Sydney Institute of Marine Science, Mossman, NSW, \\ Australia, ${ }^{4}$ Antarctic Climate and Ecosystems Cooperative Research Centre, Hobart, TAS, Australia
}

Air-breathing marine animals, such as seals and seabirds, undertake a special form of central-place foraging as they must obtain their food at depth yet return to the surface to breathe. While telemetry technologies have advanced our understanding of the foraging behavior and physiology of these marine predators, the proximate and ultimate influences controlling the diving behavior of individuals are still poorly understood. Over time, a wide variety of analytical approaches have been developed for dive data obtained via telemetry, making comparative studies and syntheses difficult even amongst closely-related species. Here we review publications using dive telemetry for 24 species (marine mammals and seabirds) in the Southern Ocean in the last decade (2006-2016). We determine the key questions asked, and examine how through the deployment of data loggers these questions are able to be answered. As part of this process we describe the measured and derived dive variables that have been used to make inferences about diving behavior, foraging, and physiology. Adopting a question-driven orientation highlights the benefits of a standardized approach for comparative analyses and the development of models. Ultimately, this should promote robust treatment of increasingly complex data streams, improved alignment across diverse research groups, and also pave the way for more integrative multi-species meta-analyses. Finally, we discuss key emergent areas in which dive telemetry data are being upscaled and more quantitatively integrated with movement and demographic information to link to population level consequences.

Keywords: diving behavior, dive variables, seals, marine mammals, penguins, data loggers, comparative analyses, Antarctica

\section{INTRODUCTION}

The Southern Ocean (hereafter SO) is a unique circumpolar biogeographic region, supporting a rich biodiversity with many species of high conservation value (De Broyer and Koubbi, 2014b). It is also one of the areas manifesting the most rapid climate-related changes (Larsen et al., 2014). The SO ecosystem supports diverse marine predators, many of which are pursuit divers (Trathan and Hill, 2016) that are particularly interesting for the study of the underlying principles related 
to foraging behavior and diving physiology. Seven species of seals are endemic to the SO, some breed on land while others use the sea-ice as breeding platform. Toothed whales (parvorder Odontoceti) may occupy the SO year round while in contrast baleen whales (parvorder Mysticeti) typically migrate and are present only seasonally. Over $90 \%$ of the SO avian biomass comprises penguins (order Sphenisciformes) (Woehler and Croxall, 1997) but a large variety of seabirds, the majority of the order Procellariiformes [e.g., prions (genus Pachytila), shearwaters (genus Puffinus), albatross (family Diomedeidae), petrels (family Procellariidae)] and of the order Charadriiformes [i.e., gulls and terns (family Laridae), skuas (family Stercorariidae)], visit the Antarctic region during the austral summer. These species are all adapted to the extreme and highly seasonal ocean-ice environment and are likely to respond differently to changing climate and other humaninduced influences and activities (Forcada et al., 2008; Constable et al., 2014).

Historically, these highly mobile animals were almost impossible to observe across their range. Today, a multitude of data loggers and sensors provide a broad observational framework for acquiring detailed information about their lives at sea. Information on how animals use the environment in space and time are the central tennants that inform a synthetic overview of ecosystem structure and dynamics (Schick et al., 2013). The demographic performance (e.g., growth rates and reproductive behavior) of these animals provides an integrated measure of overall system function and health (Barbraud and Weimerskirch, 2001). As long-lived species, marine mammals and seabirds can be monitored long-term and act as indicators of ecosystem status across a range of spatiotemporal scales (Schick et al., 2013). Since many of these species dive to several hundred meters (e.g., elephant seals (genus Mirounga, McIntyre et al., 2010) and beaked whales (family Ziphiidae; Tyack et al., 2006), they provide information from the surface to the deep ocean. Quantifying movement and diving behavior can therefore provide information on areas of high and low productivity, how these change over time, and may help provide insights into how animals will respond to global climate change.

Kooyman (1965) was the first to investigate the diving behavior of a Weddell seal (Leptonychotes weddellii) using an animal-borne device-a pressure gauge combined with a kitchen timer; the deployment lasted about an hour. This basic timedepth recorder (TDR) recorded for the first time not only dive depth and duration but also ascent and descent rates of the seal. This work revolutionized the study of marine mammals and other marine animals (Kooyman, 2004). From these origins we can now integrate in situ behavior and physical measurements to study direct links, e.g., between the characteristics of the environment (e.g., the water mass a seal uses) and animal behavior (e.g., how deep and long it dives) and performance (e.g., how often it breaths). These linkages can ultimately help to quantify how population growth rates are affected (e.g., Hindell et al., 2017; McMahon et al., 2017).

Diving predators need to acquire sufficient resources which among other factors are determined by prey distribution, abundance, and quality. These need to be balanced against their physiological constraints (e.g., oxygen stores, age/size or sex influencing diving capacity). The interplay between need and constraint is reflected in what is directly observable, and what can be measured, for example, dive behavior using data loggers. How these predators manage their dive cycle structure is the key from which inferences can be made about the "hidden" aspects of foraging and physiology (Figure 1).

In our study, we conducted a systematic literature review of publications using dive telemetry in the Southern Ocean with a focus on 2006-2016 (Supplementary Material), as this was a period of considerable study employing both well established sensors (e.g., time-depth recorders) and emerging techniques (e.g., accelerometry, animal-borne cameras). We searched for peer-reviewed literature, published in English, containing the words: dive data, tag, time-depth recorder, TDR, Southern Ocean, Antarctic, marine mammals, penguins, seabirds, seals, cetaceans, and species names. For identifying SO birds and mammals, we follow Ropert-Coudert et al. (2014). Most research data is from south of $40^{\circ} \mathrm{S}$ (De Broyer and Koubbi, 2014a,b), although some species are clearly limited to the Antarctic region (i.e., south of $60^{\circ} \mathrm{S}$ ). This substantial field of telemetry work comprises 218 studies of 24 species, including 10 species of marine mammals and 14 species of seabirds, that used a variety of different data loggers and sensors. The full literature database is made available under Supplementary Material.

Where pertinent, we do refer to literature published outside the 2006-2016 time frame, as key studies obviously occurred either before this decade, or studies were conducted on species similar to those included in this review. We do not intend this as a general review of advances in the bio-logging field (for which see, for example, Halsey et al., 2006a,b, 2007a; Mate et al., 2007; Goldbogen et al., 2013; Balmer et al., 2014; McIntyre, 2014; Ceia and Ramos, 2015; Hussey et al., 2015). Rather we aim to examine the richness of information and insights gained, from relatively simple dive data streams, about the underwater lives of Southern Ocean marine predators. While focusing on

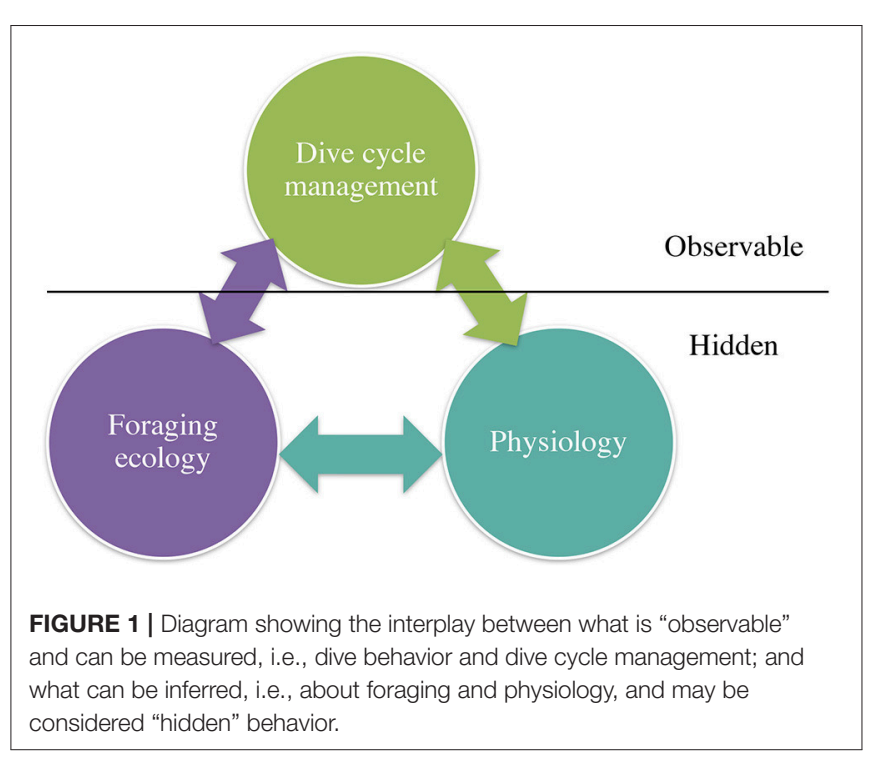


mammals or birds only (e.g., Goldbogen et al., 2013; McIntyre, 2014; Carter et al., 2016) would allow a more detailed coverage, it is timely for a more holistic perspective of the Southern Ocean. We hope this review provides a useful synthesis particularly for new researchers commencing Southern Ocean biotelemetry research.

First, we briefly cover the main observational platforms used (devices and sensors), and the general coverage across SO species and geographical areas. Following a basic explanation of diving behavior, we then synthesize the literature by adopting a question-driven approach: exploring the foraging and physiological inferences achievable using dive data. Adopting this approach organizes the insights obtained from dive telemetry under an ecological framework which, we suggest, provides a useful context for aligning the analyses of dive metrics. This perspective might thereby serve to facilitate comparative multispecies analyses and meta-analyses. The scope of the review covers what has been learnt about important SO predators, and particularly how tags, data and analytical methods were used. The review closes with a perspectives section considering the outstanding questions being addressed in emergent areas.

\section{OBSERVATIONAL PLATFORMS}

\section{Devices and Sensors}

Animal-borne data loggers enable the remote study of various aspects of the biology of free-living animals with regard to behavior, physiology and energetics (Cooke et al., 2004). Data loggers are devices that record information using sensors measuring physical (e.g., light, temperature, or pressure) or physiological properties such as heart rate (Table 1). Measuring the speed at which an animal moves helps, for example, to define the function of the dive (e.g., transit or hunting) (Naito, 2010). More detailed information about an animal's dive behavior became available with the introduction of sensors, such as gyroscopes (change in direction) (Kawabata et al., 2014), 3-axis magnetometers (orientation) (Friedlaender et al., 2011), cameras (video) (Watanabe and Takahashi, 2013), and hydrophones (sound) (Goldbogen, 2006). Further, recording in situ physical and oceanographic features while an animal is diving provides information of the habitats the animal uses for feeding, and how these may influence vertical distribution of its prey. Finally, recording physiological variables, such as heart rate and body temperature, can provide proxies for metabolism and prey consumption rates (Kuhn et al., 2006; Crossin et al., 2012) (see Table 1).

Throughout the 1970s and most of the 1980s TDRs were predominantly archival, needing to be recovered to retrieve the information. Taking into account difficulties often experienced in recapturing a tagged animal, satellite-linked depth recorders (SLDR) were developed (Bengtson et al., 1993). These typically use the Argos satellite system to relay data which, due the system's limited bandwidth, often requires high temporal resolution data to be summarized either into user-defined bins (Fedak et al., 2001, 2002) or greatly simplified time depth profiles (e.g., Photopoulou et al., 2015). Satellite-relayed information offers the only solution to studying animals without prospect of recapture,
TABLE 1 | Commercially available sensor types for data loggers and their use for marine mammal and seabird research.

\begin{tabular}{|c|c|}
\hline Sensor & Use \\
\hline Time & Activity information: duration, time of the day \\
\hline Pressure & Activity information: depth reached diving \\
\hline Acceletometer & Activity information: active swim speed \\
\hline Speed sensor & Activity information: swim velocity \\
\hline Wet/dry sensor & Activity information: in/on water \\
\hline Gyroscope & Activity information: change in direction \\
\hline Magnetometer & $\begin{array}{l}\text { Environmental information, orientation, inertia, } \\
\text { position of each sensor relative to the } \\
\text { transmitter }\end{array}$ \\
\hline Camera & $\begin{array}{l}\text { Movie information processed via image } \\
\text { processing software }\end{array}$ \\
\hline Hydrophone & Sound information \\
\hline Heart rate & Physiological information as energy expenditure \\
\hline $\begin{array}{l}\text { Stomach or esophagus } \\
\text { temperature }\end{array}$ & Physiological information as ingestion \\
\hline Temperature & Environmental information: use of currents \\
\hline Salinity & Environmental information: ocean circulation \\
\hline Light & $\begin{array}{l}\text { Environmental information, day/night, } \\
\text { seasonality }\end{array}$ \\
\hline \multicolumn{2}{|l|}{ POSITION SENSOR } \\
\hline Argos transmitter & Local-to meso-scale movement information \\
\hline $\begin{array}{l}\text { GPS (Global Positioning } \\
\text { System) }\end{array}$ & Fine-scale movement information \\
\hline $\begin{array}{l}\text { GLS (Global Location } \\
\text { Sensing) }\end{array}$ & Meso- to basin-scale movement information \\
\hline
\end{tabular}

For further information regarding scales of movement and location errors associated with different positioning sensors see: Bradshaw et al. (2007), Bryant (2007), Block et al. (2011), Costa et al. (2010), Patterson et al. (2010), Winship et al. (2012) and references therein.

such as fledglings, non-breeding individuals and/or those not bound to land (or ice) based colonies.

\section{Usage in Southern Ocean Species}

From 2006-2016, data loggers were used to study 24 airbreathing species in the SO: 7 pinnipeds, 7 penguins, 3 cetaceans, and 7 flying seabirds. Most studies focused on pinnipeds (44\%) and penguins (41\%), while studies on flying seabirds and cetaceans accounted for only 6 and $9 \%$ of publications, respectively (Table 2). The reasons for this disparity are likely due to differences in the catchability and accessibility of the different species. More than half of the species studied $(n=16)$ were subAntarctic $\left(40-60^{\circ} \mathrm{S}\right)$ species and 8 were high Antarctic species $\left(>60^{\mathrm{O}} \mathrm{S}\right)$ (Figure 2). The sampling effort was greatest in the South Atlantic.

Fourteen of 28 studies on Antarctic fur seals (Arctocephalus gazella) took place in the South Georgia region. Southern elephant seals (Mirounga leonina) were tagged mostly at breeding colonies on South Georgia, Kerguelen, Crozet, and Prince Edward islands but also at haulouts near Antarctic continental stations. Crabeater (Lobodon carcinophaga), leopard (Hydrurga leptonyx), Ross (Ommatophoca rossii), and Weddell seals were tagged on or near the continent, especially near the Antarctic 
TABLE 2 | Southern Ocean literature review results showing the number of studies conducted by species from 2006-2016.

\begin{tabular}{|c|c|c|c|c|c|}
\hline $\begin{array}{l}\text { Map } \\
\text { ID }\end{array}$ & Species & $\begin{array}{c}\text { No. } \\
\text { Studies }\end{array}$ & Dive duration (s) & Dive depth (m) & References \\
\hline \multirow[t]{2}{*}{1} & Antarctic fur seal (AFS) & 28 & $107 \pm 43$ & $31 \pm 20(12)$ & Arthur et al., 2016 \\
\hline & & & $67 \pm 4$ & $21 \pm 2(5)$ & Bestley et al., 2015 \\
\hline \multirow[t]{2}{*}{2} & Subantarctic fur seal (SFS) & 3 & $14-18$ & $5-13(78 p)$ & Verrier et al., 2011 \\
\hline & A. tropicalis & & $93 \pm 0.5$ & $100 \pm 0.3(47)^{\star}$ & Luque et al., 2007a \\
\hline \multirow[t]{3}{*}{3} & Southern elephant seal (SES) & 47 & $1103 \pm 308$ & $409 \pm 192(9)$ & Le Bras et al., 2016 \\
\hline & Mirounga leonina & & $\begin{array}{l}1560 \pm 318 \\
1488 \pm 306\end{array}$ & $\begin{array}{l}1049 \pm 315(326 \mathrm{f}) \\
1170 \pm 411(61 \mathrm{~m})\end{array}$ & Hindell et al., 2016 \\
\hline & & & $1183 \pm 326$ & $334 \pm 133(20)$ & Bestley et al., 2015 \\
\hline \multirow[t]{2}{*}{4} & Leopard seal (LS) & 4 & $132 \pm 74$ & $17 \pm 11(21)$ & Krause et al., 2016 \\
\hline & Hydrurga leptonyx & & $\mathrm{nr}$ & $62 \pm 15(7)$ & Krause et al., 2015 \\
\hline \multirow[t]{3}{*}{5} & Crabeater seal (CS) & 6 & $225 \pm 23$ & $54 \pm 27(13)$ & Bestley et al., 2015 \\
\hline & Lobodon carcinophagus & & $\mathrm{nr}$ & $\operatorname{nr}(34)$ & Friedlaender et al., 2011 \\
\hline & & & 228 & $11 \pm 5.3(34)$ & Burns and Costa, 2008 \\
\hline \multirow[t]{4}{*}{6} & Weddell seal (WS) & 12 & $489 \pm 122$ & $119 \pm 38(18)$ & Bestley et al., 2015 \\
\hline & Leptonychotes weddellii & & $1380 \pm 0.6$ & $511 \pm 4(1)$ & Heerah et al., 2015 \\
\hline & & & $1260 \pm 6$ & $475 \pm 4(1)$ & \\
\hline & & & $600 \pm 360$ & $67 \pm 54(1)$ & Heerah et al., 2014 \\
\hline 7 & $\begin{array}{l}\text { Ross seal (RS) } \\
\text { Ommatophoca rossii }\end{array}$ & 1 & $\mathrm{nr}$ & $52-100(10)$ & Blix and Nordøy, 2007 \\
\hline \multirow[t]{2}{*}{1} & King penguin (KP) & 22 & $211-248$ & $95-135(6)$ & Hanuise et al., 2013 \\
\hline & Aptenodytes patagonicus & & $1-495$ & $2-344.5(21)$ & Le Vaillant et al., 2013 \\
\hline 3 & & & $\mathrm{Nr}$ & $43.08 \pm 0.1(65)$ & Ainley and Ballard, 2012 \\
\hline \multirow[t]{3}{*}{4} & Gentoo penguins (GP) & 6 & 88 & $45.9(20)^{*}$ & Handley and Pistorius, 2015 \\
\hline & Pygoscelis papua & & $92.3-109.6$ & $35.9-52.2(7)$ & Lee et al., 2015 \\
\hline & & & $\mathrm{nr}$ & $52.7 \pm 16.0(12)$ & Kokubun et al., 2011 \\
\hline \multirow[t]{3}{*}{5} & $\begin{array}{l}\text { Chinstrap penguin (CP) } \\
\text { Pygoscelis antarctica }\end{array}$ & 8 & $\begin{array}{c}70.5 \pm 9 \\
81 \pm 13.176 .7 \pm 17.8\end{array}$ & $\begin{array}{c}29.1 \pm 6.6(20) \\
37 \pm 10.6(17) \\
33.9 \pm 12.7(20)\end{array}$ & Kokubun et al., 2015 \\
\hline & & & $62 \pm 25$ & $20 \pm 14(31)^{\star}$ & Blanchet et al., 2013 \\
\hline & & & 20 & $5(2)^{\star}$ & Mori, 2012 \\
\hline \multirow[t]{3}{*}{6} & Macaroni penguin (MP) & 13 & $130 \pm 11$ & $48 \pm 7(7)$ & Whitehead et al., 2016 \\
\hline & Eudyptes chrysolophus & & $85 \pm 36$ & $32 \pm 26(20)$ & Blanchet et al., 2013 \\
\hline & & & $40-130$ & $9-40(105)$ & Hindell et al., 2011 \\
\hline \multirow[t]{4}{*}{7} & Southern rockhooper penguin (SRP) & 4 & $\mathrm{nr}$ & $16 \pm 6(36)$ & Rosciano et al., 2016 \\
\hline & Eudyptes chrysocome & & $77.2 \pm 3.5$ & $29.7 \pm 3.4(12)$ & Ludynia et al., 2012 \\
\hline & & & $63.2 \pm 36.4$ & $20.6 \pm 19.4(4)$ & Raya Rey et al., 2009 \\
\hline & & & $71.7 \pm 5.5$ & $27.1 \pm 5.7(30)$ & Pütz et al., 2006 \\
\hline 1 & $\begin{array}{l}\text { Killer whale (KW) } \\
\text { Orcinus orca }\end{array}$ & 1 & $294.6 \pm 140.4$ & $57.5 \pm 112.5(9)$ & Reisinger et al., 2015 \\
\hline
\end{tabular}


TABLE 2 | Continued

\begin{tabular}{|c|c|c|c|c|c|}
\hline $\begin{array}{l}\text { Map } \\
\text { ID }\end{array}$ & Species & $\begin{array}{l}\text { No. } \\
\text { Studies }\end{array}$ & Dive duration (s) & Dive depth (m) & References \\
\hline \multirow[t]{3}{*}{2} & \multirow{3}{*}{$\begin{array}{l}\text { Humback whale }(\mathrm{HW}) \\
\text { Megaptera novaeangliae }\end{array}$} & 12 & $\mathrm{nr}$ & 18-64 (9) & Friedlaender et al., 2016 \\
\hline & & & $\mathrm{nr}$ & $66.1 \pm 75.1(13)$ & Tyson et al., 2016 \\
\hline & & & $\mathrm{nr}$ & $5-85(9)$ & Friedlaender et al., 2013 \\
\hline 3 & $\begin{array}{l}\text { Antarctic minke whale (MW) } \\
\text { Balaenoptera bonaerensis }\end{array}$ & 1 & $84 \pm 24$ & $18 \pm 5(2)$ & Friedlaender et al., 2014 \\
\hline \multirow[t]{2}{*}{1} & Crozet shags (CRs) & 2 & $\mathrm{nr}$ & $100-110(12)^{*}$ & Cook et al., 2008a \\
\hline & Phalacrocorax melanogenis & & 371 & $145(12)^{\star}$ & Cook et al., 2008b \\
\hline 2 & $\begin{array}{l}\text { Great shearwaters (GRs) } \\
\text { Puffinus gravis }\end{array}$ & 1 & $7.9 \pm 8.5$ & $3.3 \pm 3.8(7)$ & Ronconi et al., 2010 \\
\hline 3 & $\begin{array}{l}\text { Common diving-petrel (CMp) } \\
\text { Pelecanoides urinatrix }\end{array}$ & 1 & $10.1 \pm 4.1$ & $2.1 \pm 0.3(20)$ & Navarro et al., 2014 \\
\hline \multirow[t]{2}{*}{4} & White-chinned petrel (WHp) & 2 & $4.6 \pm 3.9$ & $2.9 \pm 2.4(9)$ & Rollinson et al., 2014 \\
\hline & Procellaria aequinoctialis & & $\mathrm{nr}$ & $3.9 \pm 1.1(14)^{\star}$ & Sue-Anne, 2012 \\
\hline 5 & $\begin{array}{l}\text { South Georgian diving petrel (SGp) } \\
\text { Pelecanoides georgicus }\end{array}$ & 1 & $14.3 \pm 4.2$ & $18.1 \pm 3.6(6)$ & Navarro et al., 2014 \\
\hline \multirow[t]{5}{*}{6} & Kerguelen shag (KEs) & 5 & $<350$ & $<120$ & Cook et al., 2013 \\
\hline & Phalacrocorax verrucosus & & 97 & $23.5(26)$ & Watanabe et al., 2011 \\
\hline & & & $87-304$ & $70-80(15)^{\star}$ & Cook et al., 2010 \\
\hline & & & $\mathrm{nr}$ & $70-80(15)^{\star}$ & Cook et al., 2008a \\
\hline & & & 321 & $108.5(15)^{\star}$ & Cook et al., 2008b \\
\hline 7 & $\begin{array}{l}\text { Imperial cormorant (IMc) } \\
\text { Phalacrocorax atriceps }\end{array}$ & 1 & $304-14$ & $65-2(12)$ & Quintana et al., 2007 \\
\hline
\end{tabular}

Examples of reported mean dive durations ( $\mathrm{sec}$ ) and mean depths $(m)$ are given as mean $\pm S D$ or range (min-max) as available. Sample sizes are given in brackets. For species with few studies ( $\leq 5)$ all references are given here, otherwise the three most recent studies are shown. Abbreviations: $n r$, numeric value not reported; $m$, males; $f$, females; $p$, pups; $j$, juveniles. In

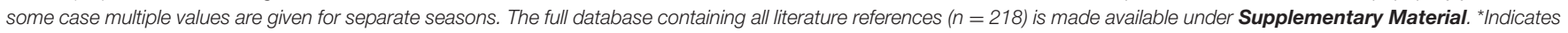
mean maximum dive depth was reported; **binned data from satellite-linked recorders.

Peninsula or near the coast on the sea ice, and occasionally on sub-Antarctic islands. Access to these dispersed ice-affiliated species remains challenging over large areas of the SO. Some $80 \%$ of studies on Adélie penguins (Pygoscelis adeliae) were carried out in Adélie Land. Macaroni penguins (E. chrysolophus) were most commonly tagged at South Georgia and sub-Antarctic islands within the Indian sector. A few rockhopper penguin (Eudyptes chrysocome) colonies off Argentina and the Falkland Islands fall within the Southern Ocean (i.e., $<40^{\mathrm{O}} \mathrm{S}$ ). Chinstrap penguins ( $P$. antarctica) were studied at sub-Antarctic islands including South Georgia, South Orkney (Takahashi et al., 2003), and South Shetland (Croll et al., 2006). Finally, emperor penguins (Aptenodytes forsteri) were studied at various colonies along the coast of the Antarctic continent (Wienecke et al., 2007). Albatrosses and diving petrels were studied at South Georgia and the South Orkney Islands (Phillips et al., 2005, 2007; Rollinson et al., 2014). The only site where the diving ability of cormorants (Phalacrocorax spp.) was studied in the last 10 years is the Crozet archipelago (Cook et al., 2008a,b). For cetaceans, the studies were carried out near the Auckland Islands, the Falkland Islands and in South America, and in the Antarctic Peninsula region.

Cetacean telemetry studies have lagged somewhat behind those of seals and penguins largely due to accessibility, as well as technological issues with tag attachments. These are resolving and beginning to provide valuable longer term tracking datasets (e.g., Reisinger et al., 2015; Weinstein and Friedlaender,
2017). Additionally, the tag design for DTAGs (multisensor archival digital acoustic recording tags, Johnson and Tyack, 2003; Goldbogen et al., 2013) provides some of the most sophisticated diving data achievable for the study of free-living animals, albeit still usually at short time scales (typically a day or so, using suction cup attachments, e.g., Tyson et al., 2016). Taking these developments into account we can expect a maturation of this field and consequent major expansion of these data over the next decade. The study of SO seabirds also largely remains focused on movement studies, often with the addition of simple wet/dry activity sensors (e.g., Phalan et al., 2007). Seabird diving studies continue only in relatively low numbers, but we may similarly expect an increase in future with the ongoing miniaturization of data loggers and sensors.

\section{THE BASICS OF DIVING BEHAVIOR}

Diving behavior occurs at a series of scales: the individual dive scale, the bout scale (being made up of a series of dives) and the trip scale (a trip from land being made up of a series of bouts). Furthermore, diving behavior can vary on different temporal scales (daily, monthly, seasonally) and may also be influenced by the lunar cycle (e.g., Horning and Trillmich, 1999; Biuw et al., 2010; Heerah et al., 2013; Guinet et al., 2014) as expanded in the next section on Foraging Inference. 


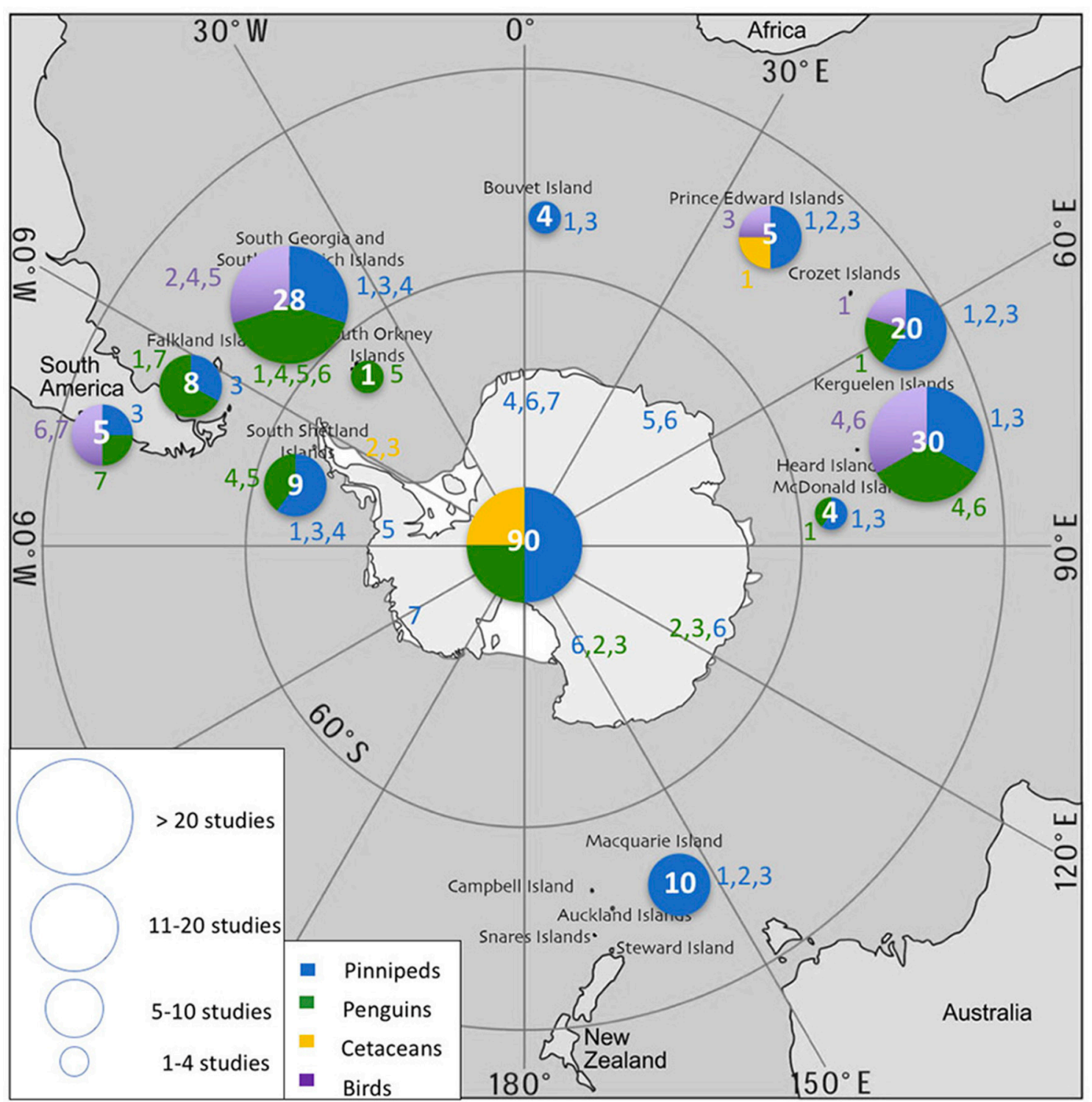

FIGURE 2 | Spatial distribution of sampling effort/data logger deployment in the Southern Ocean during 2006-2016 for each species. Circle size and white number represent the total number of studies carried out in each location. Color-coded numbers correspond to the species cited in Table 2. The database containing all literature references is made available under Supplementary Material.

Each dive can be divided into distinct phases (Figure 3). The descent phase (DESC) represents a period of active swimming using sequential, large amplitude strokes of flippers, flukes or feet to reach the desired depth (Williams et al., 2000). The bottom phase (BOT) is defined as the period between the dive descent and ascent. Often this is simplified as the time between the first and last recorded depth that is some fraction (e.g., $80 \%$, but also $60-85 \%$ depending on the species) of the maximum depth (Austin et al., 2006; Bailleul et al., 2008). Halsey et al. (2007a) proposed the definition as between the first and the last wiggle or step, being deeper than a given proportional depth threshold, assigned per species. The bottom phase is generally assumed to be connected to feeding activity. During the ascent phase (ASC) when the animal returns to the surface, it experiences a decrease in pressure and the re-inflation of the lungs (Williams et al., 2000). The final phase is the post-dive surface interval (PDSI) during which the animal replenishes its oxygen stores before a new dive (Houston, 2011). Time at the surface can also be used for preening, resting, food processing or moving to a new area (traveling or searching) (Thompson and Fedak, 2001). This is a generalized structure of a dive and a useful conceptual framework. However, in reality many dives diverge from this pattern, either having no or a greatly limited bottom phase ("V" and " $U$ " shaped dives), or multiple bottom phases at different depths (Heerah et al., 2014, 2015). 


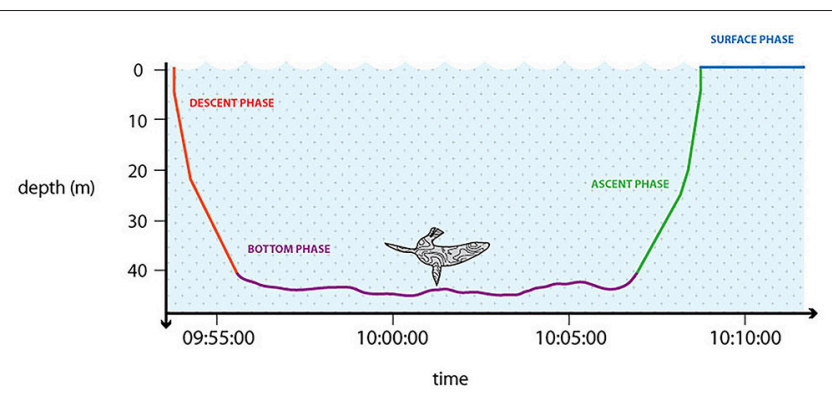

FIGURE 3 | Stylized graphic representation showing a general dive of a marine predator. The diving phases are summarized using different colors: descent phase (red); bottom phase (violet); ascent phase (green); surface phase (blue). Designed by: Charlie Armstrong.

On the basis of their profiles, dives may be classified typically as square dives (DESC = ASC with BOT); V-shaped $(\mathrm{DESC}=\mathrm{ASC}$ without $\mathrm{BOT})$; skewed right $(\mathrm{DESC}<\mathrm{ASC})$ or left dive (DESC > ASC) (Schreer et al., 2001). Among all species and groups, square dives are generally regarded as foraging dives, although Weddell seals may use V-shape dives for feeding (Fuiman et al., 2007). In contrast, left and right skewed dives generally have a different purpose and are usually performed during traveling and searching activities. However, among elephant seals skewed right dives may be linked with food processing (Crocker et al., 1997).

Individual dives often occur in clusters or bouts. Bouts as defined by Boyd and Croxall (1992) are: "a series of four or more dives not separated by a surface period exceeding a few minutes." The end of a bout is derived from the post-dive surface interval of the last dive, but can be difficult to determine. Luque and Guinet (2007b) suggested that employing a maximum likelihood estimation method delivers the most accurate means to determine when a bout has ended. Bout durations and locations can provide information on the spatial scale of prey patches (Mori, 2012), as the animal moves between successive patches (Hooker et al., 2002). Information about bouts can also be used to make inferences about foraging preferences (e.g., prey type, Elliott et al., 2008), or foraging effort (Della Penna et al., 2015).

A trip comprises the entire time an animal spends at sea from the time it leaves land (or sea ice) to the time it returns; generally many dive bouts are performed during this period. Depending on the species and breeding status, trips may range from several days to many weeks, and short and long trips may be alternated (e.g., Chaurand and Weimerskirch, 1994; Croxall and Davis, 1999; Luque et al., 2007a; Green et al., 2009a). At the Kerguelen and Crozet islands, rockhopper penguins performed daily trips during the brooding period, but as chicks grew older trip durations increased (Tremblay and Cherel, 2005). For some taxa, such as cetaceans or pack-ice seals, the concept of a trip is not necessarily as well defined but can be regarded as the time spent moving between regions to which they demonstrate some fidelity. For example, Antarctic seal-hunting (B type) killer whales (Orcinus orca) from the Antarctic Peninsula make periodic round trips to the South American coasts and back probably for physiological maintenance rather than for feeding or breeding purpose (Durban and Pitman, 2012).

Multiple factors including body condition (e.g., Miller et al., 2012; Richard et al., 2014; Gordine et al., 2015), age (Le Vaillant et al., 2012, 2013), sex (Beck et al., 2003; Baird et al., 2005), life history stage (Schulz and Bowen, 2004; Verrier et al., 2011), and body size (Irvine et al., 2000; Mori, 2002; Navarro et al., 2014) can all influence an animal's diving behavior. An example of how dive capabilities (depth and duration) vary across SO species is presented in Figure 4. In general, larger seabirds and marine mammals dive longer and deeper than smaller species (Schreer et al., 2001). However, there are exceptions: for example, among petrels and albatrosses, smaller species tend to diver deeper in relation to their body mass than larger species (Prince et al., 1994; Navarro et al., 2014).

\section{FORAGING INFERENCE}

Southern Ocean predators use diverse habitats and feed on a wide variety of prey. By understanding the diving behavior of these species we are able to address a number of key ecological questions including: What is the distribution of their prey (spatial, vertical, among habitats, and seasonally)? What is their prey type (schooling/individual, benthic, or pelagic)? What are the foraging strategies adopted? What is the prey density (relative abundance) and quality? How much is eaten? Ultimately, integrating these observations can help explain the foraging activity and success for individual animals in time and space, as well as their functional response when facing environmental changes.

\section{Prey Distribution and Type}

Marine predators change their diving behavior in relation to the spatial distribution of their prey (Thompson and Fedak, 2001). Basic information about where prey is located in the water column is obtained from simple dive depth metrics (maximum, mean, daily and seasonal variability, position relative to the ocean floor or other physical features such as seasonal mixed layer depth). Temporal patterns in these metrics can indicate whether prey species migrate vertically over a diurnal (e.g., Robison, 2003) or lunar cycle (e.g., Benoit-Bird et al., 2009). For example, gentoo penguins dive deeper during the day and shallower at night, probably to follow the vertical krill migration (Lee et al., 2015). Similarly, the large number of dives Antarctic fur seals undertake at night may be due to the shallower night time occurrence of a krill patch rather than the quality of the prey patch (Iwata et al., 2012). In general, pelagic foragers tend to dive deeper and longer during the day than at night (e.g., Weddell seals, female southern elephant seals, and Adélie and gentoo penguins; Schreer et al., 2001). Benthic foragers [e.g., blue-eyed shags (Phalacrocorax atriceps), male southern elephant seals] in general show little to no diel patterns in maximum depth and duration (Schreer et al., 2001). The depth of benthic dives is clearly determined by the bathymetry of the foraging area. At Signy Island, chinstrap and Adélie penguins hunt the same prey, but foraging chinstraps perform shallower dives than 


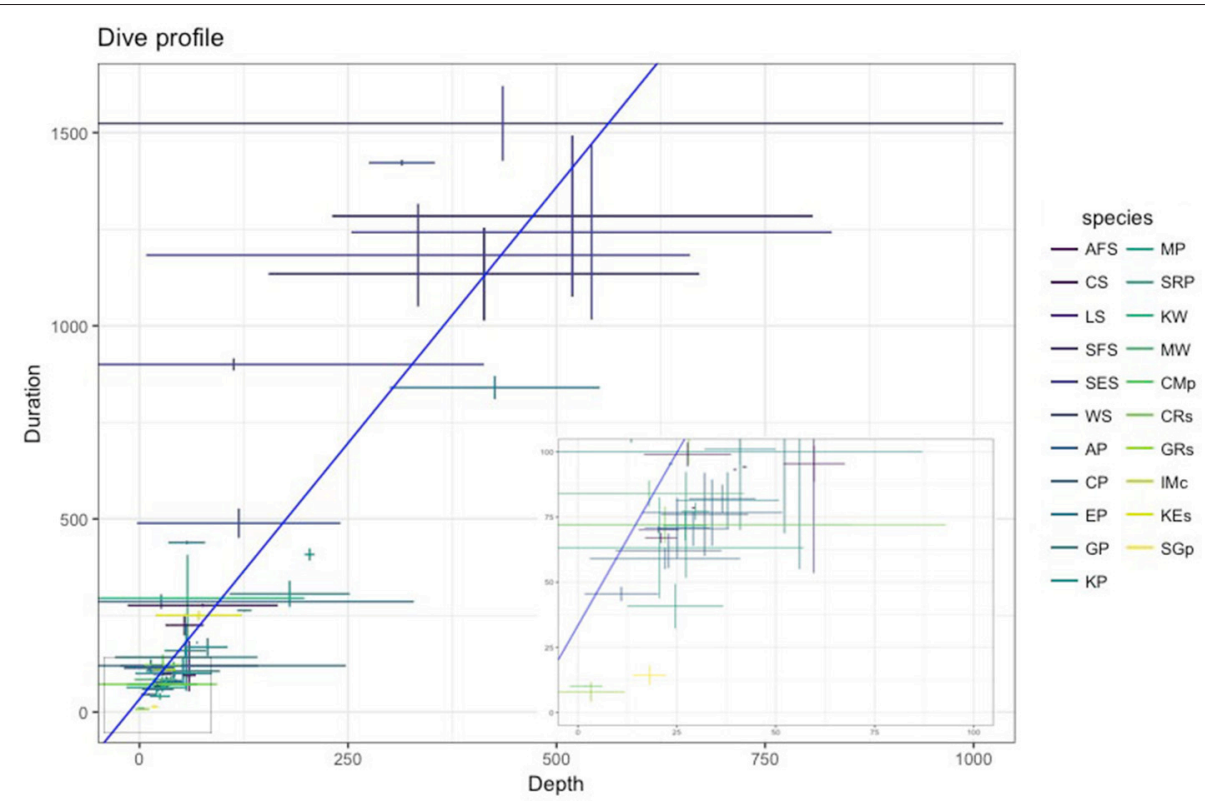

FIGURE 4 | The relationship between dive duration (s) and depth (m) across the most commonly researched SO marine predators described in Table 2 (species abbreviations given in table). Values shown as mean \pm SD. Inset panel provides a closer look at shorter ( $<100 \mathrm{~s})$ and shallower ( $<100 \mathrm{~m})$ dives. Data collected from studies undertaken between 2006-2016 (see Supplementary Material).

Adélies and feed inshore, while Adélies forage farther offshore (Takahashi et al., 2003). Interpretation of pelagic and benthic foraging behavior clearly requires a spatial context and may be hampered by poorly resolved bathymetry.

The size of prey items consumed by an animal is highly variable and not linearly related to the body size of the predator. For example, some marine predators ingest very large numbers of small prey items at a time (e.g., whales feeding on krill swarms; Kawamura, 1994) while others chase a single large prey item (e.g., Weddell seals eating large lipid-rich toothfish; Ainley and Siniff, 2009). The diet of marine mammals and seabirds has traditionally been studied through of the enumeration of stomach contents and/or scats, and is increasingly approached though methods, such as fatty-acid analyses (Pierce and Boyle, 1991), stable isotope signatures (Cherel et al., 2007; Cherel, 2008) and DNA-based methods (Deagle et al., 2007; McInnes et al., 2016, 2017). Such information may be powerfully integrated with tracking data to provide a spatial context (e.g., Bailleul et al., 2010; Walters et al., 2014), and dive data may also be used to infer what SO species consume (Hocking et al., 2017).

Dive bout duration and inter-bout intervals can provide a relative indication of the size of prey patches and dispersion of prey types (Boyd and Croxall, 1996; Mori, 1998). Depending on the particular predator and prey combination, a bout may correspond to a single or multiple prey patches. Bout types or structures may be differentiated by combined parameters, such as timing (day/night/dusk), length (short/long), and depth (shallow/deep) (e.g., Boyd et al., 1994; Lea et al., 2002), and can help discriminate the prey item(s) that are being targeted by a predator (e.g., Elliott et al., 2008). Bout duration and timing between bouts can provide information on the temporal distribution of foraging patches (Luque et al., 2008). In a study of provisioning Adélie penguins, Watanuki et al. (2010) found longer dive bouts tended to occur toward the end of foraging trips, and were associated with higher meal mass. Combined information on dive depth distribution and dive bout characteristics (e.g., proportion of dives in a bout, number of dives per bout, bout type) can identify prey as being epipelagic (e.g., surface-swarming krill; Lee et al., 2015), or mesopelagic (e.g., myctophid fish and cephalopod species; Georges et al., 2000 ), and whether prey are more aggregated (high number of dives per bout) or dispersed (low number of dives per bout) (Lea et al., 2002).

Without ascribing bout structure, Hart et al. (2010) focussed on the autocorrelation in raw TDR data (depth and time) as an indicator of the persistence or periodicity of dive behaviors in macaroni penguins. Evidence for foraging flexibility or prey switching may come from high variability and/or temporal (e.g., seasonal) changes in individual dive (Deagle et al., 2007) or bout (Harcourt et al., 2002) characteristics which can be difficult to detect. When animals are large enough, prey selection can be directly observed using miniature cameras mounted on a data logger, as has been done successfully on Antarctic fur seals (Hooker et al., 2002, 2015; Heaslip and Hooker, 2008). Cameras were also deployed on gentoo and Adélie penguins foraging on krill and fishes schooling underneath sea ice (Takahashi et al., 2008; Watanabe and Takahashi, 2013). Using cameras in combination with a number of sensors in Weddell seals, Madden et al. (2015) documented alternative foraging behaviors (deep anaerobic and shallow aerobic dives) both exploiting the same prey type [Antarctic silverfish (Pleuragramma antarcticum)], and hypothesized an energy-saving strategy where the seals were 
exploiting shallow schools of silverfish. However, animal-borne videos typically represent short observation periods relative to other behavioral records, and efficient image storage and processing methods are currently an active area of research.

\section{Foraging Strategies}

Optimal foraging theory (OFT) (Stephens and Krebs, 1986) is a conceptual framework widely employed to examine the strategies animals use to acquire food. Under the OFT framework, animal movement and behaviors are expected to be as efficient as possible. Translated to air-breathing divers, OFT suggests these animals should minimize the costs associated with feeding underwater (e.g., dive transit time, oxygen consumption) and maximize the benefits using some fitness related criterion (e.g., time spent at foraging depths, net energy gain or energy efficiency, load size, prey capture rate) (Kramer, 1988; Houston and Carbone, 1992; Mori, 1998). The most commonly developed dive optimality models are "time allocation models" (Houston, 2011) that seek to optimize the foraging and surfacing time of animals in response to changing conditions, such as prey depth (Mori and Boyd, 2004) or prey encounter rate (Thompson and Fedak, 2001). In the latter case, Thompson and Fedak (2001) investigated the effects of a "giving up" rule to demonstrate cases where a net benefit was obtained by terminating dives that are likely to be unproductive. While this general held true for shallow divers, it was unclear for deep divers such as southern elephant seals. Moreover, in the controlled environment of captive experiments where the model was tested on gray seals (Halichoerus grypus), it was not clear if the effect held true in all situations (Sparling et al., 2007).

Time-depth recorders and other bio-logging tools such as accelerometers have allowed OFT models to be developed, and predictions tested, across a wide array of free-ranging marine predators. A non-exhaustive list of applications to SO species include Antarctic fur seals (Mori and Boyd, 2004), southern elephant seals (Gallon et al., 2013), Adélie penguins (Watanabe et al., 2014), macaroni and gentoo penguins (Mori and Boyd, 2004), king penguins (A. patagonicus) (Hanuise et al., 2013), humpback (Megaptera novaeangliae) (Tyson et al., 2016) and fin (Balaenoptera physalus) whales (Acevedo-Gutiérrez et al., 2002; outside SO). The results of Acevedo-Gutiérrez et al. (2002), who compared observed TDR dive times to those predicted by an OFT model, suggested that the foraging strategies of fin whales are energetically expensive and limit the dive time of these large predators. More recently, Tyson et al. (2016) tested a suite of OFT models for humpback whales foraging at the western Antarctic Peninsula using high-resolution multi-sensor data loggers. They found that the agreement between observed and optimal behaviors varied widely depending on the physiological and behavioral values used to derive optimal predictions, and highlighted the need for an improved understanding of cetacean physiology.

In their seminal paper, Mori et al. (2005) used an optimality framework to derive prey indices from Weddell seal diving profiles, in conjunction with prey richness estimates from animal-borne camera data. The authors generally found positive correlations between these two indices (dive profiles and prey richness), but highlighted the importance of identifying the relationship between the diving behavior of predators and the type of prey they take (see above) in order to estimate prey abundance using diving profiles. Smaller numbers of larger prey are sufficient in terms of energy intake; for example, a single large high-quality items such as Antarctic toothfish (Dissosichus mawsoni) delivers possibly more energy per ingestion than smaller prey like Antarctic silverfish which may require several dives to obtain the same amount of biomass comparable to a single toothfish. However, there may be an increased energetic cost when digesting one large prey item whose temperature is much lower than that of the predator's core (see Prey consumption, below).

Dive profiles can also provide more general information on predation strategies, for example whether foraging animals approach their prey from above or below. Using a timedepth-speed logger, Ropert-Coudert et al. (2000) reported steep acceleration events where king penguins swam rapidly upwards mainly during the bottom and early ascent phases of dives. This appears to reflect an upward-looking attack strategy, whereby prey is detected and approached from below. It is likely that multiple prey approach and capture techniques are employed by individuals, depending on factors, such as light, bioluminescence and seasonal progressions in prey type, and abundance and density. Antarctic marine predators seem to employ active-search hunting rather than ambush (sit-and-wait) strategies, although a passive-gliding approach from above the prey target has been recently documented in elephant seals (Jouma'a et al., 2017). Using time-depth data in conjunction with animal-borne video, Krause et al. (2015) reported novel observations on foraging leopard seals such as unique prey-specific hunting tactics when targeting Antarctic fur seal pups and fishes including stalking, flushing, and ambush behaviors.

\section{Prey Density and Quality}

Drawing mainly from the OFT framework, a large research effort has focused on developing indices from diving telemetry data of predators that can provide information on prey quality or density.

For example, if animals reduce transit time in a patch, then changes in basic components of the dive, such as descent and ascent rates, might be indicative of patch quality, where rates increase when patch quality is high (Thompson and Fedak, 2001). Steep descent and ascent angles may assist to reduce transit time. In general, deeper dives are associated with steeper angles and higher transit rates, and may be the result of more predictably distributed prey at greater depths, as may be the case over shelf areas (Pütz et al., 2006) or at the base of the mixed layer in oceanic areas (Georges et al., 2000). There is some support for the optimality expectation using in situ measurements of patch quality (as determined from relative body lipid content, high quality areas being indicated from lipid gain): female southern elephant seals from Macquarie Island descended and ascended faster in high-quality patches than in low quality patches (Thums et al., 2013). However, this was not achieved by increasing speed or dive angle, but rather the relative body lipid content was an 
important predictor of dive behavior (e.g., Thums et al., 2013; Richard et al., 2014; Jouma’a et al., 2015).

Similarly, a straightforward interpretation under an optimality framework might expect maximized time spent at the bottom of a dive to represent greater prey density and/or quality and enhanced foraging benefit for marine predators. Many indices have been derived to investigate bottom time relationships (Table 3) attempting to account for deeper dives in the water column that necessarily take more time, with less time subsequently to be spent at the bottom. These include dive residuals (Bestley et al., 2015), residual bottom time (Dragon et al., 2012), and residual "first bottom time" (Bailleul et al., 2008). The latter attempts to translate classical first passage time (Fauchald and Tveraa, 2003), widely used to analyse area-restricted search in horizontal movements, into the vertical dimension.

Validation with external datasets has not clearly resolved whether longer bottom phases are indicative of higher or lower prey quality or density, and hence foraging success. For example, short-term measurements of head jerks in southern elephant seals using accelerometers suggested increased prey capture attempts with increased bottom durations (Gallon et al., 2013). However, in Antarctic fur seals, the relationship between head jerks and dive metrics-including bottom duration-varied markedly with temporal scale (i.e., dive to all-night scale) (Viviant et al., 2014). In a related study, Viviant et al. (2016) showed Antarctic fur seals adjust their time in the dive bottom phase mainly according to prey patch accessibility (depth) and their physiological constraints (behavioral aerobic dive limit), rather than their prey encounters (mouth-opening events). In king penguins, heart rate loggers showed increased heart rates, and hence energetic costs, associated with shorter dive durations, shorter bottom times, and longer surface durations (Halsey et al., 2007b). Similar patterns in elephant and Weddell seals appear to represent high activity dives in higher quality areas (Bestley et al., 2015). Furthermore, faster descent speeds, shorter dive durations, and reduced bottom times in higher-quality habitat were linked to body condition indices of elephant seals (Thums et al., 2013). Longer dive and bottom durations occurred when patches were of relatively low quality consistent with the predictions of the marginal value theorem (MVT, Charnov, 1976). Qualitative support for the MVT has also been provided for Adélie penguins, with opposing effects of patch-quality on duration at the dive- (positive) and bout- scale (negative), respectively (Watanabe et al., 2014). The way predators balance their dive budgets in terms of transit speed, bottom duration, and surface intervals is likely a function of interacting factors, such as the quality, size, vertical distribution and behavior of the prey, and the optimal approach will be changeable with preyswitching as discussed above. Bottom durations may also differ markedly between habitats-benthic, epipelagic or midwaterwith potentially longer bottom phases during benthic dives (e.g., gentoo penguins, see Kokubun et al., 2010).

The complexity of diving depth profiles has been widely investigated to make inferences about feeding activities. In particular, the vertical undulations or "wiggles"-changes in swim direction occurring at depth-are indicators of prey encounter rates or prey capture attempts. These are commonly simply counted (e.g., Bost et al., 2007), although a number of metrics have been developed to evaluate vertical sinuosity of dives (e.g., Dragon et al., 2012) and optimally allocate segments within dives as "hunting" or "transit" time on the basis of sinuosity thresholds (e.g., Heerah et al., 2014, 2015). Validations of such depth variations as feeding proxies have been based on various external measurements including oesophageal temperature (Adélie and king penguins, Bost et al., 2007), stomach temperature (southern elephant seals, Horsburgh et al., 2008), and accelerometers to detect mouth opening events (king penguins, Hanuise et al., 2010; Antarctic fur seals, Viviant et al., 2014). These studies generally reported good correspondence between dive profile variations and other more direct measures of feeding activity. However, not all vertical undulations are prey encounters, not all encounters have an undulation, and only a proportion of prey encounters result in capture and ingestion. Consequently, in free-living animals it remains difficult to validate the actual success of prey encounters or capture attempts as unsuccessful attempts may still result in ingestion of cold water. Thus, the above mentioned variables ought to be considered mainly as indicators of forage effort rather than forage success.

\section{Prey Consumption}

A key question with regard to dynamics of ecosystems is how much food is eaten by marine predators. To obtain actual information on foraging success requires ancilliary data to simple dive traces. Short-term direct observations of feeding activity can be obtained with tag-mounted cameras (Mori et al., 2005; Watanabe and Takahashi, 2013). As mentioned briefly above, methods like stomach or oesophageal temperature sensors for seabirds (Bost et al., 2007, 2015; Hanuise et al., 2010) and seals (Austin et al., 2006; Horsburgh et al., 2008; Kuhn et al., 2009) can provide information on prey capture attempts; since birds and mammals in the SO have a higher core body temperature than their prey, their stomach temperature drops during ingestion (Wilson et al., 1992). However, unsuccessful attempts may still result in ingestion of cold water and need to be clearly distinguished from successful feeding events. Head or jaw mounted accelerometers and speed sensors have also been used to provide feeding proxies in several seal species (Weddell, Naito et al., 2010; Antarctic fur, Iwata et al., 2012; southern elephant, Gallon et al., 2013; Guinet et al., 2014; Richard et al., 2014; Vacquié-Garcia et al., 2015), and penguins (king, Hanuise et al., 2010; chinstrap and gentoo, Kokubun et al., 2011).

Typically, feeding telemetry delivers smaller sample sizes; the data series are more complex, difficult to obtain and shortterm relative to TDR time-series. Also, issues still remain to be solved on how to keep the sensors in place. Therefore, efforts have been made to develop predictive models from the feeding indices that may be applied across longer dive time-series to estimate prey items from time-depth data alone (e.g., Simeone and Wilson, 2003; Horsburgh et al., 2008; Viviant et al., 2010; Labrousse et al., 2015). For example, Labrousse et al. (2015) developed predictive models for Prey Encounter Events using high-resolution accelerometer data and used these to predict 
TABLE 3 | Examples of derived dive parameters to investigate diving patterns, foraging behavior, and physiology of SO marine predators.

\begin{tabular}{|c|c|c|c|}
\hline Derived parameters & Question & Explanation & Examples of usage \\
\hline Dive rate or dive frequency & Diving intensity & $\begin{array}{l}\text { Number of dives per unit time (e.g., per hour of night or day; } \\
\text { per bout; per trip). }\end{array}$ & Staniland et al. (2010), Antarctic fur seals. \\
\hline Residual bottom time (RBT) & $\begin{array}{l}\text { Measure of relative } \\
\text { forage effort }\end{array}$ & $\begin{array}{l}\text { Residuals from multivariate linear regression: } \\
\text { Bottom time } \sim \text { maximum dive depth }+ \text { dive duration }\end{array}$ & $\begin{array}{l}\text { Dragon et al. (2012) southern elephant } \\
\text { seals. }\end{array}$ \\
\hline $\begin{array}{l}\text { Residual first bottom time } \\
\text { (rFBT) }\end{array}$ & $\begin{array}{l}\text { Measure of relative } \\
\text { forage effort }\end{array}$ & $\begin{array}{l}\text { Modification of the First-Passage Time (FPT) approach using } \\
\text { the RBTs described above. The variance of the RBTs is } \\
\text { calculated within circles of increasing radius (r), as } \\
\text { Var[log(t(r))], where } t(r) \text { is the sum of the absolute values of the } \\
\text { RBTs. The spatial scale of most intensive search behavior } \\
\text { determined via the maximum peak in variance. Once this } \\
\text { scale was determined, the sum of the residuals (not absolute) } \\
\text { is calculated within each circle to give rFBT values. }\end{array}$ & $\begin{array}{l}\text { Bailleul et al. (2008) southern elephant } \\
\text { seals. }\end{array}$ \\
\hline Wiggles & Foraging behavior & $\begin{array}{l}\text { Detected as anomalies in diving profiles: when an animal is } \\
\text { spending some time at a particular depth, and traveling up } \\
\text { and down while at this depth (zig-zags). }\end{array}$ & Hanuise et al. (2010) king penguins. \\
\hline Bottom sinuosity & Foraging behavior & $\begin{array}{l}\text { Calculated as the total distance swum in the bottom of the } \\
\text { dive divided by the sum of the Euclidean distances from the } \\
\text { depth at the beginning of the bottom phase to the maximum } \\
\text { depth and from there to the depth at the end of the bottom } \\
\text { phase: } \\
\text { Bottom sinuosity = } \frac{\text { Bottom Distance observed }}{\text { Bottom Distance euclidean }}\end{array}$ & $\begin{array}{l}\text { Dragon et al. (2012) southern elephant } \\
\text { seals }\end{array}$ \\
\hline Hunting time $(\mathrm{HT})$ & Foraging behavior & $\begin{array}{l}\text { Iterative application of a broken stick algorithm to identify the } \\
\text { optimum number of segments per dive, and allocation of dive } \\
\text { segments as "hunting" or "transit" using a threshold value } \\
\text { (0.9) of vertical sinuosity. }\end{array}$ & $\begin{array}{l}\text { Heerah et al. (2014) southern elephant } \\
\text { seals and Weddell seals. }\end{array}$ \\
\hline Surface residual & Measure of dive cost & $\begin{array}{l}\text { Linear Mixed Model fitted to minimum post-dive surface } \\
\text { interval (SI) observed for each (binned) dive duration (random } \\
\text { slope and intercept per individual). Residual then calculated } \\
\text { as the difference between observed and predicted values: } \\
\log \left(1+\left(\mathrm{Sl}_{\text {obs }}-\mathrm{SI}_{\text {pred }}\right) / \mathrm{SI}_{\text {pred }}\right) \text {. }\end{array}$ & $\begin{array}{l}\text { Bestley et al. (2015) southern elephant, } \\
\text { Weddell, Antarctic fur, and crabeater seals. }\end{array}$ \\
\hline Dive efficiency (DE) & Optimal diving & $\mathrm{DE}=$ bottom time/(dive duration + post-dive surface interval) & Lee et al. (2015) gentoo penguins. \\
\hline Dive:pause ratio & $\begin{array}{l}\text { Dive cycle } \\
\text { management and time } \\
\text { allocation }\end{array}$ & $\begin{array}{l}\text { The ratio of dive duration (time underwater) to time at the } \\
\text { surface: }(t+\tau) / s \text { where dive duration includes the time spent } \\
\text { foraging }(t) \text { and the round trip travel time }(\tau) \text { from the foraging } \\
\text { area to the surface. }\end{array}$ & $\begin{array}{l}\text { Houston (2011) seabirds and marine } \\
\text { mammals. }\end{array}$ \\
\hline
\end{tabular}

these events for low-resolution dive profiles available over longer periods. Informative variables included ascent speed, maximum depth, bottom time, and horizontal speed (pelagic strategy), compared with just ascent speed and dive duration (demersal strategy).

These modeling approaches may greatly increase the utility of both data types and provide some indicator of feeding activity over whole migration trips. However, information on actual feeding success is available in very few cases for free-living animals. One high-profile example is how buoyancy changes associated with relative lipid content measured from drift dive data in elephant seals (northern, Crocker et al., 1997; Robinson et al., 2010; and southern, Biuw et al., 2003; Bailleul et al., 2007; Thums et al., 2008, 2013; Gordine et al., 2015), with changes in passive vertical drift rates, provide an integrated in situ measure of foraging success. This approach has given insight 
into the location and charactersitics of successful Southern Ocean foraging areas (Biuw et al., 2007; Hindell et al., 2016), and was incorporated into population-level models integrating the physiological and movement ecology of predators (Schick et al., 2013; New et al., 2014). Efforts have been made to validate relationships between descent rates and drift rates (Richard et al., 2014), which represent a promising extension of inference to basic dive profiles and potentially broader application across other species. A recent study on Antarctic fur seals (Jeanniarddu-Dot et al., 2017) incorporated information of prey capture attempts into an energetics framework to estimate foraging efficiency and the consequences for reproductive success (pup growth). Such applications, linking individual foraging behavior with demographic consequences (see also Hiruki-Raring et al., 2012), are important avenues for future biotelemetry research in the Southern Ocean.

Overall, relatively simple dive data streams continue to provide increasingly powerful insights into marine predator foraging. However, when used alone these telemetry data remain largely limited to providing information on effort. Dive metrics cannot confirm success; indeed dive metrics (e.g., residuals: positive and negative from a fitted relationship) may be obtained from an animal that in fact fails to forage at all. Combined usage of TDRs with other devices that provide more direct observations (e.g., accelerometers, miniature cameras, speed turbines, internal sensors), even on a subset of individuals, greatly assists in maximizing inference. In addition, the caveats of inferring from dive data may be alleviated by combining data from different sources, such as isotopes and DNA methods (diet), mass or lipid gain (success), reproductive outputs (energetic costs) thereby achieving a broader perspective on the foraging of Southern Ocean marine predators.

\section{INTRINSIC DETERMINANTS OF DIVING-PHYSIOLOGICAL INFERENCE}

The foraging strategies adopted by marine predators are not only dictated by prey abundance and distribution but also by intrinsic factors, such as oxygen stores, metabolism, body size, and age (Kooyman and Ponganis, 1998; Costa, 2007; Ponganis et al., 2009; Ponganis, 2011; Castellini, 2012; Elliott, 2016). Relatively few data have been collected on the at-sea metabolism of marine birds and mammals given the practical difficulties of collecting respiration and activity data in the field. Consequently, much of what is known has been inferred from simple dive data. Information on dive duration and post-dive surface intervals provide valuable insights into diving metabolic rate, and on how animals balance time underwater using oxygen stores with time on the surface replenishing them, i.e., dive cycle management. Determining how these intrinsic factors scale with size, sex or age of the animal are key questions that remain largely unanswered. This section discusses how the use of classic dive data information provides valuable insights into dive energetics and the physiological adaptations of SO marine animals, drawing also upon examples from temperate species in a few cases.

\section{Physiological Determinants and Constraints}

Castellini (2012) and Ponganis and Kooyman (2000) reviewed the physiological adaptations among marine mammals and polar seabirds, respectively. We provide a summary here as a base for the following discussion. Many animals dive, but deep divers face a number of challenges, such as the increase in pressure with the resulting mechanical compression of tissue and gas-filled spaces, and the lack of ad libitum access to oxygen (Kooyman and Ponganis, 1998; Costa, 2007; Ponganis, 2011). The former is to some extent dealt with using morphological adaptations, such as flexible rib cages (e.g., Cozzi et al., 2010) and collapsable lungs (e.g., Falke et al., 1985; McDonald and Ponganis, 2012), while the lack of continuous access to oxygen requires a complex suite of physiological adaptations.

A number of adaptations evolved convergently among marine mammals and seabirds to enable deep diving, but there are also important differences, for example with regard to the distribution of oxyen stores in the body and the reliance on anaerobic metabolism (see below). These animals depend on adaptions that increase intrinsic oxygen stores. Body size is one factor which influences both oxygen storage and metabolic rate or oxygen use (e.g., Noren and Williams, 2000). Furthermore, to expand their breath holding capacity, deep divers have large volumes of blood. For example, in Weddell seals about $14 \%$ of their body weight is due to blood; this is 631 for a $450 \mathrm{~kg}$ seal, or $140 \mathrm{ml} \mathrm{kg}^{-1}$ (Zapol, 1996). In comparison, in humans blood makes up only about $7 \%$ of body weight (Zapol, 1996). In penguins, the blood volume is less than in seals; emperor penguins comprise about $100 \mathrm{ml}$ blood per kg body weight (Ponganis et al., 1997a), and for Adélie penguins the value is about $93 \mathrm{ml} \mathrm{kg}^{-1}$ (Lenfant et al., 1969).

Oxygen stores are also increased through increased concentrations of the oxygen-carrying proteins hemoglobin ( $\mathrm{Hb}$, in blood) and myoglobin ( $\mathrm{Mb}$, in muscle). The size of the total oxygen store and the proportions in which it is compartimentalized differ among species. Weddell seals have

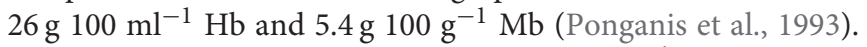
In comparison, Adélie penguins $16 \mathrm{~g} 100 \mathrm{ml}^{-1} \mathrm{Hb}$ (Lenfant

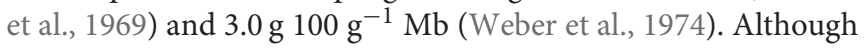
hemoglobin concentrations in emperor penguins are similar to

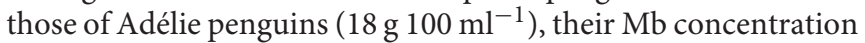

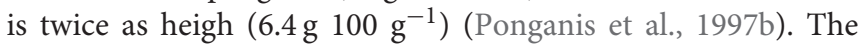
three major compartments are the respiratory and vascular systems and muscles. Generally, marine mammals carry most of their oxygen stores in the blood and muscle tissue, but again there are species specific differences. The percentage distribution of oxygen among Weddell seals (body mass $\sim 400 \mathrm{~kg}$ ) is $66 \%$ in blood, $29 \%$ in muscle and only $5 \%$ is available through the respiratory system. For the smaller Californian sea lions (Zalophus californianus) $(\sim 35 \mathrm{~kg})$ the values are 45,34 , and $21 \%$ for blood, muscle, and respiratory system, respectively (Kooyman and Ponganis, 1998). In comparison, Adélie penguins $(\sim 5 \mathrm{~kg})$ store most of their oxygen in the respiratory system (45\%), and only $29 \%$ in blood and $26 \%$ in muscle tissue. The larger emperor penguin $(\sim 25 \mathrm{~kg})$ has values more similar to the sea lion with 34 and $47 \%$ oxygen in blood and muscle, 
respectively, and only $19 \%$ in the respiratory system (Kooyman and Ponganis, 1998).

The regulation of oxygen use during dives underlies complex physiological processes and depends on a variety of factors, such as dive depth and duration, level of muscle activity (Hindle et al., 2010), and body temperature (Kooyman and Ponganis, 1998). Air-breathing diving vertebrates adjust oxygen consumption through a process known as the "dive response," a process characterized by a drop in heart rates, decreased blood perfusion of organs (except the brain) and a drop in body temperature (Butler and Woakes, 2001); the result is an overall reduction of oxygen consumption. The dive response essentially manages how long an animal can stay submerged, how much oxygen it has available, and the rate at which this oxygen is consumed. Since in deep diving endotherms a great concentration of oxygen is stored in the muscles (see above), the reduction of the blood flow causes a hypoxia facilitating the oxygen dissociation from myoglobin. This mechanism enhances aerobic metabolism in exercising muscles, despite the reduced blood flow during diving (Davis, 2014). If oxygen stores become depleted during a dive, animals can switch to anaerobic metabolism. However, anaerobic production of energy (glycolysis) is less efficient than aerobic pathways as less adenosine triphosphate (ATP, highenergy molecule) is produced and the muscle tissues accumulate lactic acid. Excessive amounts of lactic acid result in metabolic acidosis and consequently severe depression of the heart and the central nervous system (Wildenthal et al., 1968; Siesj, 1988). To remove lactic acid the animal must pay an oxygen debt. This is commonly achieved by spending extended periods at the surface to re-oxygenate tissues (Kooyman et al., 1980) which in turn can reduce foraging time and limit opportunities (Butler, 2006). However, it can be advantageous for individuals to incur such a metabolic debt.

The change from aerobic to anaerobic metabolism is determined by the Aerobic Dive Limit (ADL), i.e., the time an animal can remain submerged before levels of lactate exceed those present when an animal is resting (Kooyman, 1985). Postdive partial pressures of oxygen in venous blood $\left(\mathrm{P}_{\mathrm{O} 2}\right)$ were measured in free-living Weddell seals and bottlenose dolphins (Tursiops truncatus) and ranged from 15-20 mmHg (Ridgway et al., 1969; Ponganis et al., 1993) which is less than the values obtained from terrestrial mammals after intense exercise (27$34 \mathrm{mmHg}$; e.g., Taylor et al., 1987). Among free-diving emperor penguins, $\mathrm{P}_{\mathrm{O} 2}$ levels were $<20 \mathrm{mmHg}$ in $29 \%$ of dives and even dropped to 1-6 mmHg at times (Ponganis et al., 2007). Blood oxygen stores were also nearly completely exhausted in northern elephant seals (M. angustirostris) in whom venous $\mathrm{P}_{\mathrm{O} 2}$ was recuded to $2-10 \mathrm{mmHg}$ after dives that lasted $>10 \mathrm{~min}$ (Meir et al., 2009). To withstand such extreme levels of hypoxemia various adaptations such as an enlarged density of capillaries are necessary, but these are not yet fully understood (Ponganis et al., 2007). Some species constantly exceed their estimated ADL. In a review of 6 marine predators at South Georgia, all species except Antarctic fur seals $(\leq 5 \%)$, frequently surpassed their estimated ADL (Boyd and Croxall, 1996). Benthically feeding otariids [e.g., Australian sea lions (Nephoca cinerea)] tended to exceed their ADL more often than pelagically foraging species (e.g., Antarctic fur seals, Costa et al., 2004). Female southern elephant seals went beyond their calculated ADL in $40 \%$ of dives, in comparison with only $1 \%$ in males (Hindell et al., 1992). Emperor (20\% of dives, Butler, 2004), king (20\% of dives, Kooyman et al., 1992) and gentoo penguins (40-50\% of dives, Williams et al., 1992) also regularly exceeded their ADL, as did Macquarie shags ( $P$. purpurascens) (e.g., 19\% of male dives, Kato et al., 2000) and blue-eyed shags (36\% of dives; Boyd and Croxall, 1996). The pattern of few anaerobic dives observed among fur seals might be consistent with the maintenance of a high metabolic rate while diving, whereas the bimodality observed in other species suggests fundamentally different strategies may be used to regulate oxygen consumption between short and long dives (Boyd and Croxall, 1996). More recent work has focused on anatomical adaptions and dive capacity (Meir et al., 2008; Ponganis et al. 2009; 2010b; Wright et al., 2014). However, little has been done to empirically determine the ADL for any Southern Ocean species.

Longer post-dive surface intervals do not always indicate an oxygen debt. Even after aerobic dives, the time required to reoxigenate tissues may be longer after extended dives due to the mechanical restrictions of respiration and airway structure. The "dive:pause ratio" measures the ratio of dive duration to time at the surface. Larger ratios indicate that post-dive surface intervals are long relative to the dive, reflecting the relatively greater time required to replenish oxygen stores. Cormorants have to spend more time at the surface after longer dives, resulting in a dive:pause ratio equal to 1 (Lea et al., 1996). Gentoo penguins have a dive:pause ratio for deep dives of 1.2-2.2 and of 0.3-0.4 for shallow dives (Williams et al., 1992).

Elephant seals did not have appreciably longer surface intervals even for the longest dives; irrespective of the preceding dive, surface intervals last typically only $2-3 \mathrm{~min}$ (Hindell et al., 1992). This was considerably shorter than the 50 min surface intervals made by Weddell seals known to have exceeded their ADL (Kooyman et al., 1980). This provides strong evidence that many, if not all, of the female elephant seal dives that surpassed their calculated ADL were in fact aerobic. Thus, the diving metabolic rate of elephant seals may be less than the allometrically derived estimates of metabolic rate used in the calculation of the ADL. Reduced metabolic rate during diving is a well-known consequence of the dive reflex, and the simple metric of dive depth and PDSI can be used to infer the magnitude of this reduction, at least in aerobic dives. The estimate of the metabolic rate in emperor penguins, which was relatively low when foraging, could be used to calculate with a better approximation the ADL for this species than the $\mathrm{O}_{2}$ store data (Nagy et al., 2001). This has implications for energetic models commonly used in ecosystem and fisheries models, as deep diving predators may use less energy than expected from allometric estimations.

Basic diving data (dive and surface duration), along with estimates of total body oxygen stores and metabolic rate, can provide the basis for quantifying dive limits of an individual. These may address fundamental bio-physiology questions for species-specific studies and also be relevant for those focussing on broader ecological questions and ecosystem energy flow studies (Williams et al., 2000). Data loggers can also provide 
insights into the mechanisms that underpin the dive response. Simple time depth data are insufficient to demonstrate some types of behaviors, but augmentation with an additional sensors (such as velocity from accelerometers) expands the capacity for inference. For example, accelerometers in combination with TDRs revealed that southern elephant and Weddell seals use strategies, such as passive sinking and burst-glide swimming, to reduce their oxygen consumption during diving (Hindell et al., 2000; Williams et al., 2000). Kerguelen shags (P. verrucosus) adapt their stroking activity depending on the body buoyancy variation (Cook et al., 2010). A similar mechanism is used by cetaceans (whales, Acevedo-Gutiérrez et al., 2002; dolphins, Williams et al., 2017).

\section{Behavioral Mechanisms as Proxies for Physiological Mechanisms}

An animal's buoyancy plays an important role in diving; increased buoyancy provides challenges for animals during descent and is energetically expensive, given that animals require additional work, for example, to maintain their position in the water column (Webb et al., 1998). However, buoyancy varies at a range of temporal scales, firstly within an individual annual cycle (e.g., gestation in elephant seals, Crocker et al., 1997) and also throughout its life as an animal grows and develops different traits (e.g., becoming a dominant male for elephant seals, Galimberti et al., 2007). Buoyancy can, however, also be used as a measure of an animal's body condition because lipids are less dense than water making fatter animals more buoyant than leaner conspecifics (Miller et al., 2012). Some species perform "drift" dives where they stop swimming and are stationary in the water column. The rate and direction of drift has been related to the animal's total lipid content at that time (Biuw et al., 2003). This means that spatio-temporal dynamics of lipid gain (and loss) can be measured, identifying regions of poor and good foraging. An analysis of elephant seal drift data from many of the major breeding sites indicated that some regions such as the Antarctic Circumpolar Current frontal systems in the Atlantic sector may be better quality habitat than other sectors of the SO. For example, seals from the declining Macquarie Island population had to travel for over a month to reach prime habitats (Biuw et al., 2007). Finer-scale measurements of burst and glide behavior have also been used to measure changes in buoyancy, opening the use of this approach to a wide range of species (Williams et al., 2000; Oliver et al., 2013; Jouma'a et al., 2015).

Tri-axial accelerometers were employed to measure overall dynamic body acceleration (ODBA) which is considered a proxy for energy expended by animals during different diving phases (Wilson et al., 2006; Gleiss et al., 2011). Acceleration is used to measure movement, and since muscle motion involves oxygen consumption, acceleration could be used as a proxy for $\mathrm{O}_{2}$ consumption itself. When foraging, Magellanic penguins descended faster than they ascended, which means their descent phase was energetically much costlier than their return to the surface (Wilson et al., 2010). Previous studies conducted on cormorants and pinnipeds have shown how ODBA offers a better estimation of energy expenditure than doubly labeled water method (Wilson et al., 2006; Fahlman et al., 2008) or flipper stroke evaluation (Jeanniard-du-Dot et al., 2016). However, ODBA is best used for quantifying energy during individual diving phases only rather than the full foraging trip (Wilson et al., 2010) because it might be affected by animal mass, number of strokes, and the relationship between heart rate and $\mathrm{O}_{2}$ consumption (e.g., change of heart rate during dive response).

Other sensors can measure an animal's physiology more directly. Heart rate can be measured with externally (Hindell and Lea, 1998; Elmegaard et al., 2016) or subcutanerously (Meir et al., 2008; Wright et al., 2014) mounted electrodes or acoustic transmitters (Green et al., 2005). Heart rate loggers can demonstrate the degree of bradycardia during diving and anticipatory tachycardia before PSDI (Wright et al., 2014). In elephant seals, heart rates can drop to lower than 10 beats $\mathrm{min}^{-1}$, even during active dives (Andrews et al., 1997). The degree of bradycardia is negatively related to dive duration, so that longer dives have lower heart rates once they pass a certain threshold duration. If the relationship between heart rate and metabolic rate is known, heart rate can be used to estimate metabolic rate during an animal's time at sea (see Green, 2011 for a full review). This approach has been used successfully for several species of penguin (Froget et al., 2002; Green et al., 2005, 2009b; Meir et al., 2008). It requires an initial calibration of the heart rate/metabolic rate relationship, usually in a laboratory, followed by deployment of the heart rate loggers that record heart rate continuously. Based on this approach, the field metabolic rate of macaroni penguins has been estimated to be $9.03 \pm 0.39 \mathrm{~W} \mathrm{~kg}^{-1}$, three times the estimated Basal Metabolic Rate (Green et al., 2002). The utility of using heart rate to measure metabolic rate is hampered by technical issues such as device attachment, as well as the need for the relationship to be calibrated in the lab for each individual (Butler et al., 2004).

In summary, even simple dive data can provide valuable insights into how diving animals manage their oxygen stores and the implications that this has for diving metabolic rate. Nonetheless, more complex data streams are required to address these questions in a fully quantative way. Additional sensors, such as accelerometers and heart rate recorders, can quantify energy expenditure. However, to obtain accurate estimates laboratory based calibrations are likely to be needed (Green et al., 2007), and the logistic difficulties of doing this in the Antarctic may explain why this has rarely been done on Southern Ocean species. Understanding the underlying mechanisms that control metabolism requires even more specialized equipment, for example to enable serial blood samples to measure oxygen levels (McDonald and Ponganis, 2013). For this work, the isolated hole experimental paradigm is something that is well suited to Antarctic field studies, at least for some species (Ponganis et al., 2010a, 2011), and it is to be hoped that more of this work will be conducted in the future.

\section{PERSPECTIVES AND EMERGENT AREAS}

The aim of this review was to examine the foraging behavior and physiology of marine mammals and seabirds of the SO using data 
loggers as the main method for collecting the information. The last decade has seen substantial progress in this endeavor, and we now have a solid understanding of these factors for many SO birds and mammals. However, as certain questions are answered, others emerge and a number of key areas are a focus for further work; in this final section we highlight some of these.

Adopting a question-based approach, as we have done in this review, helps to provide a framework so there is a logical flow for how dive analyses may be carried out, depending on the biological or ecological question that is driving the research. Obviously, a massive suite of diving variables is available to be utilized in such analyses, and there is a proliferation of approaches used to infer foraging behavior and diving physiology. Advancements in analytical and statistical approaches, together with generally increasing sample sizes, are providing improved tools for learning more about diving ecology. An excellent example is the now readily accessible software for implementing mixed-effect models (e.g., Wood and Scheipl, 2017; Pinheiro et al., 2018). These enable inferences to be made at the individual level (via the random effects), as well as at the population level (via the fixed effects) while taking account of individual variability. Such techniques provide an appropriate analytical framework for researchers to deal with large, serially (spatially and temporally) correlated, and individual-based datasets, and are increasingly being adopted. Advancements in computationally efficient approaches for fitting models with discrete latent states to time series data, which have been widely used in animal movement modeling (Langrock et al., 2012; Michelot et al., 2016), may similarly promise a step-function in improving capabilities for dive analyses in the near future (e.g., Quick et al., 2017). Finally, hierarchical approaches, enabling information from multiple data sources to be integrated, are also available (Clark, 2007) and present important opportunities particularly for population-level analyses which we return to at the close of this section.

An important research area this review has considered only incidentally is the association of animal diving with the physical environment. This is largely beyond our scope since the vast majority of telemetry studies investigating how the environment influences the foraging and physiology of Southern Ocean marine predators (i.e., bottom-up processes) do so by integrating spatially-explicit movement (location) data with external habitat information (e.g., from satellite remote sensing, and/or oceanographic models). However, significant advances have been made over the last decade through the in situ collection of environmental data by animalborne sensors, which has opened our eyes to the subsurface environment in a way that is not possible from remotelysensed data. A prime example is the improved knowledge of how elephant seals use specific water masses and oceanographic features obtained from high-quality temperature-salinity profiles collected onboard tags (e.g., Biuw et al., 2007; Labrousse et al., 2015; Hindell et al., 2016). Other novel approaches include the usage of onboard light-levels (Guinet et al., 2014) to infer bio-optical properties of the water column, including phytoplankton concentrations (Jaud et al., 2012; O'Toole et al., 2014), as well as direct fluorometry measurements (Guinet et al., 2013) to evaluate productivity influences on animal foraging. These clearly demonstrate the benefits gained from collecting environmental information onboard the same tag that is collecting the behavioral (dive) information. The coupling of oceanographic studies with ecological studies is an opportunity that has not reached its full potential yet, but this growing area likely warrants a review in its own right.

Our improved understanding of the at-sea vertical movements, foraging strategies and prey distributions now needs to be placed into a larger population and community context. This has three components. The first upscaling is to combine multiple species-specific studies to obtain community level assessments of diving behavior. This approach is increasingly being adopted in tracking work in the SO (Friedlaender et al., 2011; Thiebot et al., 2012; Raymond et al., 2015; Reisinger et al., 2018) and is providing powerful insights into regions that are of particular ecological significance. However, this only applies to the horizontal dimension (latitude and longitude), and dive studies will enable this approach to move into a third dimension-depth (e.g., Hindell et al., 2011). An integrated understanding of how diving animals use the water column will enable us to identify key features, such as the deep scattering layer (Naito et al., 2013), thermoclines (Bost et al., 2015) and specific water masses (Biuw et al., 2007) that are important to the community of diving predators. This can be matched to highly resolved modern Regional Ocean Models (e.g., Malpress et al., 2017) to estimate how access to prey and foraging efficiencies may change into the future.

Upscaling can also be in a temporal sense. Long time series of diving data sets enable us to address questions of environmental determinants of foraging success and prey distribution (see Trathan et al., 1996; Hindell et al., 2017). Data-logging has the potential to play a key role in ecological monitoring (IMOS reference, Hussey et al., 2015), but this requires long-term funding, which in the past has been difficult to secure for tagging studies.

Better linkage of diving and location data will also lead to better understanding of habitat usage of SO bird and mammals. Describing and modeling of key habitats has been a focus of research for a long time but emerging statistical methods are now able to integrate diving behavior into movement models. For example, Bestley et al. (2015) incorporated several diving indices (dive residual, surface residual) into a statespace movement model to study at-sea foraging behavior. There was a general tendency for the probability of switching into "resident" movement state to be positively associated with shorter dive durations (for a given depth) and longer postdive surface intervals (for a given dive duration), potentially indicating high energy diving. A growing body of literature demonstrates that simplistic interpretations of optimal foraging theory, based only on horizontal movements, do not directly translate into the vertical dimension in dynamic marine environments. Analyses that incorporate dive data can test more sophisticated models of foraging behavior. Further efforts to integrate multiple data streams (e.g., movement, haulout, diving activity) and thereby represent more realistic movement behaviors (such as at-sea 
resting) can also lead to improved at-sea activity budgets (Russell et al., 2015; Bestley et al., 2016).

Currently bio-logging studies remain somewhat limited in their scope given that most still focus largely on observations of individual animals that are then extrapolated across the population. This is mainly because instruments are expensive and consequently sample sizes are small. But with increasing availabilty of inexpensive GPS loggers, light sensors, and accelerometers it is increasingly possible to achieve large samples. A related question is how many individuals need to be tagged to obtain a population level measure while still minimizing the number of animals that are equipped. Several studies of habitat use have approached this by making cumulative area curves (sequentally increasing the number of animals and calculating the total area used) (Hindell et al., 2003; Arthur et al., 2017). Our new insights into foraging at sea also need to be linked to demography and population level consequences. For many SO species, broad-scale relationships between demographic performance parameters, such as breeding success and recruitment in relation to climate variables (e.g., ice extent and ocean temperature), are well established for some species - Adélie penguins and ice at the western Antarctic Peninsula (Smith et al., 2003), and elephant seals and the Southern Ocean oscillation index (Le Boeuf and Crocker, 2005). But the proximate drivers of these relationships are not clear. Tagging studies have the potential to bridge this gap. For example, the diving behavior of female Antarctic fur seals is linked to prey availabilty, and forage location, diving activity, diet, and foraging efficiency all change significantly between years as ocean conditions vary (Lea and Dubroca, 2003; Lea et al., 2006). In warmer years, mothers dive deeper and make longer foraging trips. This reduces both maternal and pup body condition, and surpresses pup growth rates (Lea et al., 2006). Increasingly sophisticated approaches are enabling diving behavior to be linked into energetics (Jeanniarddu-Dot et al., 2017) and predator-prey (Hiruki-Raring et al., 2012) frameworks to estimate reproductive consequences at the

\section{REFERENCES}

Acevedo-Gutiérrez, A., Croll, D. A., and Tershy, B. R. (2002). High feeding costs limit dive time in the largest whales. J. Exp. Biol. 205, 1747-1753.

Ainley, D. G., and Ballard, G. (2012). Non-consumptive factors affecting foraging patterns in Antarctic penguins: a review and synthesis. Polar Biol. 35, 1-13. doi: 10.1007/s00300-011-1042-x

Ainley, D. G., and Siniff, D. B. (2009). The importance of Antarctic toothfish as prey of Weddell seals in the Ross Sea. Ant. Sci. 21, 317-327. doi: 10.1017/S0954102009001953

Andrews, R. D., Jones, D. R., Williams, J. D., Thorson, P. H., Oliver, G. W., Costa, D. P., et al. (1997). Heart rates of northern elephant seals diving at sea and resting on the beach. J. Exp. Biol. 200, 2083-2095.

Arthur, B., Hindell, M., Bester, M., De Bruyn, P. N., Trathan, P., Goebel, M., et al. (2017). Winter habitat predictions of a key Southern Ocean predator, the Antarctic fur seal (Arctocephalus gazella). Deep-Sea Res. Pt II Top. Stud. Oceanogr. 140, 171-181. doi: 10.1016/j.dsr2.2016.10.009

Arthur, B., Hindell, M., Bester, M. N., Oosthuizen, W. C., Wege, M., and Lea, M. A. (2016). South for the winter? Within-dive foraging effort reveals the trade-offs between divergent foraging strategies in a free-ranging predator. Funct. Ecol. 30, 1623-1637. doi: 10.1111/1365-2435.12636

Austin, D., Bowen, W. D., McMillan, J. I., and Iverson, S. J. (2006). Linking movement, diving, and habitat to foraging success in a large marine predator. population level. These expand important research avenues as biotelemetry in the Southern Ocean enters its mature phase. Finally, linking at-sea behavior to demography and population level consequences that are now much more feasible will provide an advance on traditional individual-based studies and provide an overaching view of how behavior is linked to population growth and persistence.

\section{AUTHOR CONTRIBUTIONS}

All authors contributed substantively to writing the manuscript. GR conducted the literature review under the supervision of $\mathrm{MH}$, SB, BW, CM.

\section{FUNDING}

GR is recipient of a Tasmania Graduate Research Scholarship and Elite Research Top-up both provided by the University of Tasmania; SB is the recipient of an Australian Research Council Australian Discovery Early Career Award (project number DE180100828) funded by the Australian Government.

\section{ACKNOWLEDGMENTS}

We thank R. Tyson for providing us with useful comments on the earlier version of the manuscript. This review would not have been possible without the many decades of dedicated research by many researchers. We thank them all for their hard work and vision.

\section{SUPPLEMENTARY MATERIAL}

The Supplementary Material for this article can be found online at: https://www.frontiersin.org/articles/10.3389/fmars. 2018.00464/full\#supplementary-material

Ecology 87, 3095-3108. doi: 10.1890/0012-9658(2006)87[3095:LMDAHT]2.0. $\mathrm{CO} ; 2$

Bailleul, F., Authier, M., Ducatez, S., Roquet, F., Charrassin, J. B., Cherel, Y., et al. (2010). Looking at the unseen: combining animal bio-logging and stable isotopes to reveal a shift in the ecological niche of a deep diving predator. Ecography 33, 709-719. doi: 10.1111/j.1600-0587.2009.06034.x

Bailleul, F., Charrassin, J. B., Monestiez, P., Roquet, F., Biuw, M., and Guinet, C. (2007). Successful foraging zones of southern elephant seals from the Kerguelen Islands in relation to oceanographic conditions. Philos. Trans. R. Soc. Lond. B 362, 2169-2181. doi: 10.1098/rstb.2007.2109

Bailleul, F., Pinaud, D., Hindell, M., Charrassin, J. B., and Guinet, C. (2008). Assessment of scale-dependent foraging behaviour in southern elephant seals incorporating the vertical dimension: a development of the first passage time method. J. Anim. Ecol. 77, 948-957. doi: 10.1111/j.1365-2656.2008. 01407.x

Baird, R. W., Hanson, M. B., and Dill, L. M. (2005). Factors influencing the diving behaviour of fish-eating killer whales: sex differences and diel and interannual variation in diving rates. Can. J. Zool. 83, 257-267. doi: 10.1139/z05-007

Balmer, B. C., Wells, R. S., Howle, L. E., Barleycorn, A. A., McLellan, W. A., Ann Pabst, D., et al. (2014). Advances in cetacean telemetry: a review of singlepin transmitter attachment techniques on small cetaceans and development of a new satellite-linked transmitter design. Mar. Mammal Sci. 30, 656-673. doi: $10.1111 / \mathrm{mms} .12072$ 
Barbraud, C., and Weimerskirch, H. (2001). Emperor penguins and climate change. Nature 411, 183-186. doi: 10.1038/35075554

Beck, C. A., Bowen, W. D., McMillan, J. I., and Iverson, S. J. (2003). Sex differences in the diving behaviour of a size-dimorphic capital breeder: the grey seal. Anim. Behav. 66, 777-790. doi: 10.1006/anbe.2003.2284

Bengtson, J. L., Croll, D. A., and Goebel, M. E. (1993). Diving behaviour of chinstrap penguins at Seal Island. Antarct. Sci. 5, 9-15. doi: 10.1017/S0954102093000033

Benoit-Bird, K. J., Dahood, A. D., and Würsig, B. (2009). Using active acoustics to compare lunar effects on predator-prey in two marine mammal species. Mar. Ecol. Progr. Ser. 395, 119-135. doi: 10.3354/meps07793

Bestley, S., Jonsen, I. D., Harcourt, R. G., Hindell, M. A., and Gales, N. J. (2016). Putting the behaviour into animal movement modelling: improved activity budgets from use of ancillary tag information. Eco. Evol. 6, 8243-8255. doi: $10.1002 /$ ece 3.2530

Bestley, S., Jonsen, I. D., Hindell, M. A., Harcourt, R. G., and Gales, N. J. (2015). Taking animal tracking to new depths: synthesizing horizontal-vertical movement relationships for four marine predators. Ecology 96, 417-427. doi: 10.1890/14-0469.1

Biuw, M., Boehme, L., Guinet, C., Hindell, M., Costa, D., Charrassin, J. B., et al. (2007). Variations in behavior and condition of a Southern Ocean top predator in relation to in situ oceanographic conditions. Proc. Nat. Acad. Sci. U.S.A. 104, 13705-13710. doi: 10.1073/pnas.0701121104

Biuw, M., McConnell, B., Bradshaw, C. J. A., Burton, H., and Fedak, M. (2003). Blubber and buoyancy: monitoring the body condition of freeranging seals using simple dive characteristics. J. Exp. Biol. 206, 3405-3423. doi: $10.1242 /$ jeb.00583

Biuw, M., Nøst, O. A., Stien, A., Zhou, Q., Lydersen, C., and Kovacs, K. M. (2010). Effects of hydrographic variability on the spatial, seasonal and diel diving patterns of southern elephant seals in the eastern Weddell Sea. PLoS ONE 5:e13816. doi: 10.1371/journal.pone.0013816

Blanchet, M., Biuw, M., Hofmeyr, G., de Bruyn, P., Lydersen, C., and Kovacs, K. (2013). At-sea behaviour of three krill predators breeding at BouvetøyaAntarctic fur seals, macaroni penguins and chinstrap penguins. Mar. Ecol. Prog. Ser. 477, 285-302. doi: 10.3354/meps10110

Blix, A. S., and Nordøy, E. S. (2007). Ross seal (Ommatophoca rossii) annual distribution, diving behaviour, breeding and moulting, off Queen Maud Land, Antarctica. Polar Biol. 30, 1449-1458. doi: 10.1007/s00300-007-0306-y

Block, B. A., Jonsen, I. D., Jorgensen, S. J., Winship, A. J., Shaffer, S. A., Bograd, S. J., et al. (2011). Tracking apex marine predator movements in a dynamic ocean. Nature 475:86. doi: 10.1038/nature10082

Bost, C. A., Cotté, C., Terray, P., Barbraud, C., Bon, C., Delord, K., et al. (2015). Large-scale climatic anomalies affect marine predator foraging behaviour and demography. Nat. Commun. 6:8220. doi: 10.1038/ncomms9220

Bost, C. A., Handrich, Y., Butler, P. J., Fahlman, A., Halsey, L. G., Woakes, A. J., et al. (2007). Changes in dive profiles as an indicator of feeding success in king and Adélie penguins. Deep-Sea Res. Pt II Top. Stud. Oceanogr. 54, 248-255. doi: 10.1016/j.dsr2.2006.11.007

Boyd, I. L., Arnould, J. P., Barton, T., and Croxall, J. P. (1994). Foraging behaviour of Antarctic fur seals during periods of contrasting prey abundance. J. Anim. Eco. 63, 703-713. doi: 10.2307/5235

Boyd, I. L., and Croxall, J. P. (1992). Diving behaviour of lactating Antarctic fur seals. Can. J. Zool. 70, 919-928. doi: 10.1139/z92-131

Boyd, I. L., and Croxall, J. P. (1996). Dive durations in pinnipeds and seabirds. Can. J. Zool. 74, 1696-1705. doi: 10.1139/z96-187

Bradshaw, C. J., Sims, D. W., and Hays, G. C. (2007). Measurement error causes scale-dependent threshold erosion of biological signals in animal movement data. Ecol. Appl. 17, 628-638. doi: 10.1890/06-0964

Bryant, E. (2007). 2D Location Accuracy Statistics for Fastloc Cores Running Firmware Versions 2.2 \& 2.3. Wildtrack Telemetry Systems Ltd.

Burns, J. M., and Costa, D. P. (2008). Does aerobic dive capacity constrain winter diving behavior in crabeater seals? FASEB J. 22(1 Supplement), 1239-1243.

Butler, P. J. (2004). Metabolic regulation in diving birds and mammals. Respir. Physiol. Neurobiol. 141, 297-315. doi: 10.1016/j.resp.2004.01.010

Butler, P. J. (2006). Aerobic dive limit. What is it and is it always used appropriately? Comp. Biochem. Physiol. A Mol. Integr. Physiol. 145, 1-6. doi: $10.1016 /$ j.cbpa.2006.06.006
Butler, P. J., Green, J. A., Boyd, I. L., and Speakman, J. R. (2004). Measuring metabolic rate in the field: the pros and cons of the doubly labelled water and heart rate methods. Funct. Ecol. 18, 168-183. doi: 10.1111/j.0269-8463.2004.00821.x

Butler, P. J., and Woakes, A. J. (2001). Seasonal hypothermia in a large migrating bird: saving energy for fat deposition? J. Exp. Biol. 204, 1361-1367. Available online at: http://jeb.biologists.org/content/204/7/1361.short

Carter, M. I. D., Bennett, K. A., Embling, C. B., Hosegood, P. J., and Russell, D. J. (2016). Navigating uncertain waters: a critical review of inferring foraging behaviour from location and dive data in pinnipeds. Mov. Ecol. 41:25. doi: 10.1186/s40462-016-0090-9

Castellini, M. (2012). Life under water: physiological adaptations to diving and living at sea. Compr. Physiol. 2, 1889-1919. doi: 10.1002/cphy.c110013

Ceia, F. R., and Ramos, J. A. (2015). Individual specialization in the foraging and feeding strategies of seabirds: a review. Mar. Biol. 162, 1923-1938. doi: 10.1007/s00227-015-2735-4

Charnov, E. L. (1976). Optimal foraging, the marginal value theorem. Theor. Popul. Biol. 9, 129-136. doi: 10.1016/0040-5809(76)90040-X

Chaurand, T., and Weimerskirch, H. (1994). The regular alternation of short and long foraging trips in the blue petrel Halobaena caerulea: a previously undescribed strategy of food provisioning in a pelagic seabird. J. Anim. Ecol. 63, 275-282. doi: 10.2307/5546

Cherel, Y. (2008). Isotopic niches of emperor and Adélie penguins in Adélie Land, Antarctica. Mar. Biol. 154, 813-821. doi: 10.1007/s00227-008-0974-3

Cherel, Y., Hobson, K. A., Guinet, C., and Vanpe, C. (2007). Stable isotopes document seasonal changes in trophic niches and winter foraging individual specialization in diving predators from the Southern Ocean. J. Anim. Ecol. 76, 826-836. doi: 10.1111/j.1365-2656.2007.01238.x

Clark, J. S. (2007). Models for Ecological Data. An Introduction. Princeton, NJ: Princeton University Press.

Constable, A. J., Melbourne-Thomas, J., Corney, S. P., Arrigo, K. R., Barbraud, C., Barnes, D. K., et al. (2014). Climate change and Southern Ocean ecosystems: how changes in physical habitats directly affect marine biota. Glob Change Biol. 20, 3004-3025. doi: $10.1111 / \mathrm{gcb} .12623$

Cook, T. R., Bailleul, F., Lescroël, A., Tremblay, Y., and Bost, C. A. (2008a). Crossing the frontier: vertical transit rates of deep diving cormorants reveal depth zone of neutral buoyancy. Mar. Biol. 154, 383-391. doi: 10.1007/s00227-008-0939-6

Cook, T. R., Kato, A., Tanaka, H., Ropert-Coudert, Y., and Bost, C. A. (2010). Buoyancy under control: underwater locomotor performance in a deep diving seabird suggests respiratory strategies for reducing foraging effort. PLOS ONE 5:e9839. doi: 10.1371/journal.pone.0009839

Cook, T. R., Lescroel, A., Cherel, Y., Kato, A., and Bost, C.-A. (2013). Can foraging ecology drive the evolution of body size in a diving endotherm? PLoS ONE 8:e56297. doi: 10.1371/journal.pone.0056297

Cook, T. R., Lescroël, A., Tremblay, Y., and Bost, C. A. (2008b). To breathe or not to breathe? Optimal breathing, aerobic dive limit and oxygen stores in deep- diving blue-eyed shags. Anim. Behav. 76, 565-576. doi: 10.1016/j.anbehav.2008.02.010

Cooke, S. J., Hinch, S. G., Wikelski, M., Andrews, R. D., Kuchel, L. J., Wolcott, T. G., et al. (2004). Biotelemetry: a mechanistic approach to ecology. Trends Ecol. Evol. 19, 334-343. doi: 10.1016/j.tree.2004.04.003

Costa, D. (2007). "Diving physiology of marine vertebrates," in eLS, (Chichester: John Wiley and Sons Ltd). doi: 10.1002/9780470015902.a0004230

Costa, D. P., Kuhn, C. E., Weise, M. J., Shaffer, S. A., and Arnould, J. P. Y. (2004). When does physiology limit the foraging behaviour of freely diving mammals? Int. Congr. Ser. 1275, 359-366. doi: 10.1016/j.ics.2004.08.058

Costa, D. P., Robinson, P. W., Arnould, J. P., Harrison, A. L., Simmons, S. E., Hassrick, J. L., et al. (2010). Accuracy of ARGOS locations of pinnipeds at-sea estimated using Fastloc GPS. PLoS ONE 5:e8677. doi: 10.1371/journal.pone.0008677

Cottin, M., Chastel, O., Kato, A., Debin, M., Takahashi, A., Ropert-Coudert, Y., et al. (2014). Decreasing prolactin levels leads to a lower diving effort but does not affect breeding success in Adélie penguins. Horm. Behav. 65, 134-141. doi: 10.1016/j.yhbeh.2013.12.001

Cozzi, B., Mazzariol, S., Podestu, M., and Zotti, A. (2010). Diving adaptations of the cetacean skeleton. Open Zool. J. 2, 24-32. doi: 10.2174/18743366009020 10024 
Crocker, D. E., Boeuf, B. J. L., and Costa, D. P. (1997). Drift diving in female northern elephant seals: implications for food processing. Can. J. Zool. 75, 27-39. doi: 10.1139/z97-004

Croll, D. A., Demer, D. A., Hewitt, R. P., Jansen, J. K., Goebel, M. E., and Tershy, B. R. (2006). Effects of variability in prey abundance on reproduction and foraging in chinstrap penguins (Pygoscelis antarctica). J. Zool. 269, 506-513. doi: $10.1111 / j .1469-7998.2006 .00090 . x$

Crossin, G. T., Trathan, P. N., Phillips, R. A., Gorman, K. B., Dawson, A., Sakamoto, K. Q., et al. (2012). Corticosterone predicts foraging behavior and parental care in macaroni penguins. Am. Nat. 180, E31-E41. doi: $10.1086 / 666001$

Croxall, J. P., and Davis, L. S. (1999). Penguins: paradoxes and patterns. Mar. Ornithol. 27, 1-12.

Davis, R. W. (2014). A review of the multi-level adaptations for maximizing aerobic dive duration in marine mammals: from biochemistry to behavior. J. Comp. Physiol. B. Biochem. Syst. Environ. Physiol. 184, 23-53. doi: 10.1007/s00360-013-0782-Z

De Broyer, C., and Koubbi, P. (2014a). "Introduction," in Biogeographic Atlas of the Southern Ocean (Cambridge: Scientific Committee on Antarctic Research), 1-10.

De Broyer, C., and Koubbi, P. (eds.). (2014b). Biogeographic Atlas of the Southern Ocean. Cambridge: Scientific Committee on Antarctic Research. doi: 10.1017/S0954102015000140

Deagle, B. E., Gales, N. J., Evans, K., Jarman, S. N., Robinson, S., Trebilco, R., et al. (2007). Studying seabird diet through genetic analysis of faeces: a case study on macaroni penguins (Eudyptes chrysolophus). PLoS ONE 2:831. doi: 10.1371/journal.pone.0000831

Della Penna, A., De Monte, S., Kestenare, E., Guinet, C., and d'Ovidio, F. (2015). Quasi-planktonic behavior of foraging top marine predators. Sci. Rep. 5:18063. doi: $10.1038 /$ srep 18063

Dragon, A., Bar-Hen, A., Monestiez, P., and Guinet, C. (2012). Horizontal and vertical movements as predictors of foraging success in a marine predator. Mar. Ecol. Prog. Ser. 447, 243-257. doi: 10.3354/meps09498

Durban, J. W., and Pitman, R. L. (2012). Antarctic killer whales make rapid, roundtrip movements to subtropical waters: evidence for physiological maintenance migrations? Biol. Lett. 8, 274-277. doi: 10.1098/rsbl.2011.0875

Elliott, K. H. (2016). Measurement of flying and diving metabolic rate in wild animals: review and recommendations. Comp. Biochem. Physio. Part A: Mol. Integr. Physiol. 202, 63-77. doi: 10.1016/j.cbpa.2016.05.025

Elliott, K. H., Woo, K., Gaston, A. J., Benvenuti, S., Dall'Antonia, L., and Davoren, G. K. (2008). Seabird foraging behaviour indicates prey type. Mar. Ecol. Prog. Ser. 354, 289-303. doi: 10.3354/meps07221

Elmegaard, S. L., Johnson, M., Madsen, P. T., and McDonald, B. I. (2016). Cognitive control of heart rate in diving harbor porpoises. Curr. Biol. 26, R1175-R1176. doi: 10.1016/j.cub.2016.10.020

Fahlman, A., Wilson, R., Svärd, C., Rosen, D. A., and Trites, A. W. (2008). Activity and diving metabolism correlate in Steller sea lion Eumetopias jubatus. Aquat. Biol. 2,75-84. doi: 10.3354/ab00039

Falke, K. J., Hill, R. D., Qvist, J., Schneider, R. C., Guppy, M., Liggins, G. C., et al. (1985). Seal lungs collapse during free diving: evidence from arterial nitrogen tensions. Science 229, 556-558. doi: 10.1126/science.4023700

Fauchald, P., and Tveraa, T. (2003). Using first-passage time in the analysis of arearestricted search and habitat selection. Ecology 84, 282-288. doi: 10.1890/00129658(2003)084[0282:UFPTIT]2.0.CO;2

Fedak, M., Lovell, P., McConnell, B., and Hunter, C. (2002). Overcoming the constraints of long range radio telemetry from animals: getting more useful data from smaller packages. Integr. Comp. Biol. 42, 3-10. doi: 10.1093/icb/42.1.3

Fedak, M. A., Lovell, P., and Grant, S. M. (2001). Two approaches to compressing and interpreting time-depth information as collected by timedepth recorders and satellite-linked data recorders. Mar. Mammal Sci. 17, 94-110. doi: 10.1111/j.1748-7692.2001.tb00982.x

Forcada, J., Trathan, P. N., and Murphy, E. J. (2008). Life history buffering in Antarctic mammals and birds against changing patterns of climate and environmental variation. Global Change Biol. 14, 2473-2488. doi: 10.1111/j.1365-2486.2008.01678.x

Friedlaender, A. S., Goldbogen, J. A., Nowacek, D. P., Read, A. J., Johnston, D., and Gales, N. (2014). Feeding rates and under-ice foraging strategies of the smallest lunge filter feeder, the Antarctic minke whale (Balaenoptera bonaerensis). J. Exp. Biol. 217, 2851-2854. doi: 10.1242/jeb.106682
Friedlaender, A. S., Johnston, D. W., Fraser, W. R., Burns, J., Patrick, N. H., and Costa, D. P. (2011). Ecological niche modeling of sympatric krill predators around Marguerite Bay, western Antarctic Peninsula. Deep-Sea Res. Pt II Top. Stud. Oceanogr. 58, 1729-1740. doi: 10.1016/j.dsr2.2010.11.018

Friedlaender, A. S., Johnston, D. W., Tyson, R. B., Kaltenberg, A., Goldbogen, J. A., Stimpert, et al. (2016). Multiple-stage decisions in a marine central-place forager. Royal Soc. Open Sci. 3:160043. doi: 10.1098/rsos.160043

Friedlaender, A. S., Tyson, R. B., Stimpert, A. K., Read, A. J., and Nowacek, D. P. (2013) Extreme diel variation in the feeding behavior of humpback whales along the western Antarctic Peninsula during autumn. Mar. Eco. Prog. Ser. 494, 281-289. doi: 10.3354/meps10541

Froget, G., Handrich, Y., Maho, Y. L., Rouanet, J. L., Woakes, A. J., and Butler, P. J. (2002). The heart rate/oxygen consumption relationship during cold exposure of the king penguin: a comparison with that during exercise. J. Exp. Biol. 205, 2511-2517.

Fuiman, L. A., Madden, K. M., Williams, T. M., and Davis, R. W. (2007). Structure of foraging dives by Weddell seals at an offshore isolated hole in the Antarctic fast-ice environment. Deep-Sea Res. Pt II Top. Stud. Oceanogr. 54, 270-289. doi: 10.1016/j.dsr2.2006.11.011

Galimberti, F., Sanvito, S., Braschi, C., and Boitani, L. (2007). The cost of success: reproductive effort in male southern elephant seals (Mirounga leonina). Behav. Ecol. Sociobiol. 62, 159-171. doi: 10.1007/s00265-007-0450-y

Gallon, S., Bailleul, F., Charrassin, J. B., Guinet, C., Bost, C. A., Handrich, Y., et al. (2013). Identifying foraging events in deep diving southern elephant seals, Mirounga leonina, using acceleration data loggers. Deep-Sea Res. Pt II Top. Stud. Oceanogr. 88-89, 14-22. doi: 10.1016/j.dsr2.2012.09.002

Georges, J.-Y., Tremblay, Y., and Guinet, C. (2000). Seasonal diving behaviour in lactating sub-Antarctic fur seals on Amsterdam Island. Polar Biol. 23, 59-69. doi: $10.1007 / \mathrm{s} 003000050008$

Gleiss, A. C., Wilson, R. P., and Shepard, E. L. (2011). Making overall dynamic body acceleration work: on the theory of acceleration as a proxy for energy expenditure. Methods Ecol. Evol. 2, 23-33. doi: 10.1111/j.2041-210X.2010.00057.x

Goldbogen, J. A. (2006). Kinematics of foraging dives and lunge-feeding in fin whales. J. Exp. Biol. 209, 1231-1244. doi: 10.1242/jeb.02135

Goldbogen, J. A., Friedlaender, A. S., Calambokidis, J., McKenna, M. F., and Simon, M. (2013). Integrative approaches to the study of baleen whale diving behavior, feeding performance, and foraging ecology. Bioscience 63, 90-100. doi: 10.1525/bio.2013.63.2.5

Gordine, S. A., Fedak, M., and Boehme, L. (2015). Fishing for drifts: detecting buoyancy changes of a top marine predator using a step-wise filtering method. J. Exp. Bio. 218, 3816-3824. doi: 10.1242/jeb.118109

Green, J. A. (2011). The heart rate method for estimating metabolic rate: review and recommendations. Compar. Biochem. Physiol. Part A Mol. Integr. Physiol. 158, 287-304. doi: 10.1016/j.cbpa.2010.09.011

Green, J. A., Boyd, I. L., Woakes, A. J., Warren, N. L., and Butler, P. J. (2009b). Evaluating the prudence of parents: daily energy expenditure throughout the annual cycle of a free-ranging bird, the macaroni penguin Eudyptes chrysolophus. J. Avian Biol. 40, 529-538. doi: 10.1111/j.1600-048X.2009.04639.x

Green, J. A., Butler, P. J., Woakes, A. J., and Boyd, I. L. (2002). Energy requirements of female macaroni penguins breeding at South Georgia. Funct. Ecol. 16, 671-681. doi: 10.1046/j.1365-2435.2002.00670.x

Green, J. A., Halsey, L. G., Butler, P. J., and Holder, R. L. (2007). Estimating the rate of oxygen consumption during submersion from the heart rate of diving animals. American J. Physio. Reg. Integr. Comp. Physio. 292, R2028-R2038. doi: 10.1152/ajpregu.00691.2006

Green, J. A., White, C. R., and Butler, P. J. (2005). Allometric estimation of metabolic rate from heart rate in penguins. Comp. Biochem. Physiol. A 142, 478-484. doi: 10.1016/j.cbpa.2005.09.019

Green, J. A., Wilson, R. P., Boyd, I. L., Woakes, A. J., Green, C. J., and Butler, P. J. (2009a). Tracking macaroni penguins during long foraging trips using 'behavioural geolocation'. Polar Biol. 32, 645-653.

Guinet, C., Vacquié-Garcia, J., Picard, B., Bessigneul, G., Lebras, Y., Dragon, A. C., et al. (2014). Southern elephant seal foraging success in relation to temperature and light conditions: insight into prey distribution. Mar. Ecol. Prog. Ser. 499, 285-301. doi: 10.3354/meps10660

Guinet, C., Xing, X., Walker, E., Monestiez, P., Marchand, S., Picard, B., et al. (2013). Calibration procedures and first data set of Southern Ocean chlorophyll a profiles collected by elephant seals equipped with a newly 
developed CTD-fluorescence tags. Earth System Science Data 5, 15-29. doi: 10.5194/essd-5-15-2013

Halsey, L. G., Blackburn, T. M., and Butler, P. J. (2006a). A comparative analysis of the diving behaviour of birds and mammals. Funct. Ecol. 20, 889-899. doi: 10.1111/j.1365-2435.2006.01170.x

Halsey, L. G., Bost, C. A., and Handrich, Y. (2007a). A thorough and quantified method for classifying seabird diving behaviour. Polar Biol. 30, 991-1004. doi: 10.1007/s00300-007-0257-3

Halsey, L. G., Butler, P. J., and Blackburn, T. M. (2006b). A phylogenetic analysis of the allometry of diving. Am. Nat. 167, 276-287. doi: 10.1086/499439

Halsey, L. G., Handrich, Y., Fahlman, A., Schmidt, A., Bost, C. A., Holder, R. L., et al. (2007b). Fine-scale analyses of diving energetics in king penguins Aptenodytes patagonicus: how behaviour affects costs of a foraging dive. Mar. Ecol. Prog. Ser. 344, 299-309. doi: 10.3354/meps06896

Handley, J. M., and Pistorius, P. (2015). Kleptoparasitism in foraging gentoo penguins Pygoscelis papua. Polar Biol. 39, 391-395. doi: $10.1007 /$ s00300-015-1772-2

Hanuise, N., Bost, C. A., and Handrich, Y. (2013). Optimization of transit strategies while diving in foraging king penguins. J. Zool. 290, 181-191. doi: $10.1111 /$ jzo.12026

Hanuise, N., Bost, C. A., Huin, W., Auber, A., Halsey, L. G., and Handrich, Y. (2010). Measuring foraging activity in a deep-diving bird: comparing wiggles, oesophageal temperatures and beak-opening angles as proxies of feeding. $J$. Exp. Biol. 213, 3874-3880. doi: 10.1242/jeb.044057

Harcourt, R. G., Bradshaw, C. J., Dickson, K., and Davis, L. S. (2002). Foraging ecology of a generalist predator, the female New Zealand fur seal. Mar. Ecol. Prog. Ser. 227, 11-24. doi: 10.3354/meps227011

Hart, T., Coulson, T., and Trathan, P. N. (2010). Time series analysis of biologging data: autocorrelation reveals periodicity of diving behaviour in macaroni penguins. Anim. Behav. 79, 845-855. doi: 10.1016/j.anbehav.2009.12.033

Heaslip, S. G., and Hooker, S. K. (2008). Effect of animal-borne camera and flash on the diving behaviour of the female Antarctic fur seal (Arctocephalus gazella). Deep-Sea Res. Pt I Oceanogr. Res. Papers 55, 1179-1192. doi: 10.1016/j.dsr.2008.05.006

Heerah, K., Andrews-Goff, V., Williams, G., Sultan, E., Hindell, M., Patterson, T., et al. (2013). Ecology of Weddell seals during winter: influence of environmental parameters on their foraging behaviour. Deep-Sea Res. Pt II Top. Stud. Oceanogr. 88-89, 23-33. doi: 10.1016/j.dsr2.2012.08.025

Heerah, K., Federal, U., and Grande, R. (2015). From high-resolution to lowresolution dive datasets: a new index to quantify the foraging effort of marine predators. Animal Biotelemetry 3:42. doi: 10.1186/s40317-015-0074-3

Heerah, K., Hindell, M., Guinet, C., and Charrassin, J.-B. (2014). A new method to quantify within dive foraging behaviour in marine predators. PLoS ONE 9:e99329. doi: 10.1371/journal.pone.0099329

Hindell, M. .A., Lea, M. A., Bost, C. A., Charrassin, J. B., Gales, N., Goldsworthy, S., et al. (2011). "Foraging habitats of top predators, and areas of ecological significance, on the Kerguelen Plateau," in The Kerguelen Plateau: Marine Ecosystem and Fisheries, eds G. Duhamel, and D. C. Welsford (Paris: Société française d'ichtyologie), 203-215.

Hindell, M. A., Bradshaw, C. J., Sumner, M. D., Michael, K. J., and Burton, H. R. (2003). Dispersal of female southern elephant seals and their prey consumption during the austral summer: relevance to management and oceanographic zones. J. Appl. Ecol. 40, 703-715. doi: 10.1046/j.1365-2664.2003.00832.x

Hindell, M. A., and Lea, M. A. (1998). Heart rate, swimming speed, and estimated oxygen consumption of a free-ranging southern elephant seal. Physiol. Zool. 71, 74-84. doi: 10.1086/515890

Hindell, M. A., Lea, M. A., Morrice, M. G., and MacMahon, C. R. (2000). Metabolic limits on dive duration and swimming speed in the southern elephant seal Mirounga leonina. Physiol. Biochem. Zool. 73, 790-798. doi: 10.1086/318104

Hindell, M. A., McMahon, C. R., Bester, M. N., Boehme, L., Costa, D., Fedak, M. A., et al. (2016). Circumpolar habitat use in the southern elephant seal: implications for foraging success and population trajectories. Ecosphere 7, 1-27. doi: $10.1002 /$ ecs 2.1213

Hindell, M. A., Slip, D. J., Burton, H. R., and Bryden, M. M. (1992). Physiological implications of continuous, prolonged, and deep dives of the southern elephant seal (Mirounga leonina). Can. J. Zool. 70, 370-379. doi: 10.1139/z92-055

Hindell, M. A., Sumner, M., Bestley, S., Wotherspoon, S., Harcourt, R. G., Lea, M. A., et al. (2017). Decadal changes in habitat characteristics influence population trajectories of southern elephant seals. Global Change Biol. 23, 5136-5150. doi: $10.1111 /$ gcb.13776

Hindle, A. G., Young, B. L., Rosen, D. A., Haulena, M., and Trites, A. W. (2010). Dive response differs between shallow-and deep-diving Steller sea lions (Eumetopias jubatus). J. Exp. Mar. Biol. Ecol. 394, 141-148. doi: 10.1016/j.jembe.2010.08.006

Hiruki-Raring, L. M., Ver Hoef, J. M., Boveng, P. L., and Bengtson, J. L. (2012). A Bayesian hierarchical model of Antarctic fur seal foraging and pup growth related to sea ice and prey abundance. Ecol. Appl. 22, 668-684. doi: 10.1890/11-0102.1

Hocking, D. P., Marx, F. G., Park, T., Fitzgerald, E. M., and Evans, A. R. (2017). A behavioural framework for the evolution of feeding in predatory aquatic mammals. Proc. R. Soc. B 284:20162750. doi: 10.1098/rspb.2016.2750

Hooker, S. K., Barychka, T., Jessopp, M. J., and Staniland, I. J. (2015). Images as proximity sensors: the incidence of conspecific foraging in Antarctic fur seals. Animal Biotelemetry 3:37. doi: 10.1186/s40317-015-0083-2

Hooker, S. K., Boyd, I. L., Jessopp, M., Cox, O., Blackwell, J., Boveng, P. L., et al. (2002). Monitoring the prey-field of marine predators: combining digital imaging with datalogging tags. Mar. Mammal Sci. 18, 680-697. doi: 10.1111/j.1748-7692.2002.tb01066.x

Horning, M., and Trillmich, F. (1999). Lunar cycles in diel prey migrations exert a stronger effect on the diving of juveniles than adult Galápagos fur seals. Proc. R. Soc. Lond. B Biol. Sci. 266, 1127-1132. doi: 10.1098/rspb.1999.0753

Horsburgh, J. M., Morrice, M., Lea, M. A., and Hindell, M. A. (2008). Determining feeding events and prey encounter rates in a southern elephant seal: a method using swim speed and stomach temperature. Mar. Mammal Sci. 24, 207-217. doi: 10.1111/j.1748-7692.2007.00156.x

Houston, A. I. (2011). Assessing models of optimal diving. Trends Ecol. Evol. 26, 292-297. doi: 10.1016/j.tree.2011.03.003

Houston, A. I., and Carbone, C. (1992). The optimal allocation of time during the diving cycle. Behav. Ecol. 3, 255-265. doi: 10.1093/beheco/3.3.255

Hussey, N. E., Kessel, S. T., Aarestrup, K., Cooke, S. J., Cowley, P. D., Fisk, A. T., et al. (2015). Aquatic animal telemetry: a panoramic window into the underwater world. Science 348:1255642. doi: 10.1126/science. 1255642

Irvine, L. G., Hindell, M. A., van den Hoff, J., and Burton, H. R. (2000). The influence of body size on dive duration of underyearling southern elephant seals (Mirounga entoo). J. Zool. 251, 463-471. doi: 10.1111/j.1469-7998.2000.tb00802.x

Iwata, T., Sakamoto, K. Q., Takahashi, A., Edwards, E. W. J., Staniland, I. J., Trathan, P. N., et al. (2012). Using a mandible accelerometer to study finescale foraging behavior of free-ranging Antarctic fur seals. Mar. Mammal Sci. 28, 345-357. doi: 10.1111/j.1748-7692.2011.00482.x

Jaud, T., Dragon, A. C., Garcia, J. V., and Guinet, C. (2012). Relationship between chlorophyll a concentration, light attenuation and diving depth of the southern elephant seal Mirounga leonina. PLOS ONE 7:e47444. doi: 10.1371/journal.pone.0047444

Jeanniard-du-Dot, T., Trites, A. W., Arnould, J. P., and Guinet, C. (2017) Reproductive success is energetically linked to foraging efficiency in Antarctic fur seals. PLoS ONE 12:e174001. doi: 10.1371/journal.pone. 0174001

Jeanniard-du-Dot, T., Trites, A. W., Arnould, J. P., Speakman, J. R., and Guinet, C. (2016). Flipper strokes can predict energy expenditure and locomotion costs in free-ranging northern and Antarctic fur seals. Sci. Rep. 6:33912. doi: $10.1038 /$ srep33912

Johnson, M. P., and Tyack, P. L. (2003). A digital acoustic recording tag for measuring the response of wild marine mammals to sound. IEEE J. Ocean. Eng. 28, 3-12. doi: 10.1109/JOE.2002.808212

Jouma'a, J., Le Bras, Y., Picard, B., and Guinet, C. (2017). Three-dimensional assessment of hunting strategies in a deep diving predator, southern elephant seal Mirounga leonina. Mar. Ecol. Prog. Ser. 573, 255-268. doi: $10.3354 /$ meps 12191

Jouma’a, J., Le Bras, Y., Richard, G., Vacquié-Garcia, J., Picard, B., El Ksabi, N. et al. (2015). Adjustment of diving behaviour with prey encounters and body condition in a deep diving predator: the southern elephant seal. Funct. Ecol. 30, 636-648. doi: 10.1111/1365-2435.12514

Kato, A., Watanuki, Y., Nishiumi, I., Kuroki, M., Shaughnessy, P., and Naito, Y. (2000). Variation in foraging and parental behavior of king cormorants. Auk 117, 718-730. doi: 10.1642/0004-8038(2000)117[0718:VIFAPB]2.0.CO;2 
Kawabata, Y., Noda, T., Nakashima, Y., Nanami, A., Sato, T., Takebe, T., et al. (2014). Use of a gyroscope/accelerometer data logger to identify alternative feeding behaviours in fish. J. Exp. Biol. 217, 3204-3208. doi: 10.1242/jeb.108001

Kawamura, A. (1994). "A review of baleen whale feeding in the Southern Ocean," in Forty-Fourth Report of the International Whaling Commission (Puerto Vallarta), 261-271.

Kokubun, N., Kim, J. H., Shin, H. C., Naito, Y., and Takahashi, A. (2011). Penguin head movement detected using small accelerometers: a proxy of prey encounter rate. J. Exp. Biol. 214, 3760-3767. doi: 10.1242/jeb.058263

Kokubun, N., Lee, W. Y., Kim, J. H., and Takahashi, A. (2015). Chinstrap penguin foraging area associated with a seamount in Bransfield Strait, Antarctica. Polar Sci. 9, 393-400. doi: 10.1016/j.polar.2015.10.001

Kokubun, N., Takahashi, A., Mori, Y., Watanabe, S., and Shin, H.-C. (2010). Comparison of diving behavior and foraging habitat use between chinstrap and gentoo penguins breeding in the South Shetland Islands, Antarctica. Mar. Biol. 157, 811-825. doi: 10.1007/s00227-009-1364-1

Kooyman, G. L. (1965). Techniques used in measuring diving capacities of Weddell Seals. Polar Rec. 12, 391-394. doi: 10.1017/S003224740005484X

Kooyman, G. L. (1985). Physiology without restraint in diving mammals. Mar. Mammal Sci. 1, 166-178. doi: 10.1111/j.1748-7692.1985.tb00004.x

Kooyman, G. L. (2004). Genesis and evolution of bio-logging devices: 1963-2002. Mem. Natl. Inst. Polar Res. 58, 15-22.

Kooyman, G. L., Cherel, Y., Maho, Y. L., Croxall, J. P., Thorson, P. H., and Ridoux, V. (1992). Diving behavior and energetics during foraging cycles in king penguins. Eco. Monog. 62, 143-163. doi: 10.2307/2937173

Kooyman, G. L., and Ponganis, P. J. (1998). The physiological basis of diving to depth: birds and mammals. Annu. Rev. Physiol. 60, 19-32. doi: 10.1146/annurev.physiol.60.1.19

Kooyman, G. L., Wahrenbrock, E. A., Castellini, M. A., Davis, R. W., and Sinnett, E. E. (1980). Aerobic and anaerobic metabolism during voluntary diving in Weddell seals: evidence of preferred pathways from blood chemsitry and behavior. J. Comp. Physiol. B. Biochem. Syst. Environ. Physiol. 138, 335-346. doi: 10.1007/BF00691568

Kramer, D. L. (1988). The behavioral ecology of air breathing by aquatic animals. Can. J. Zool. 66, 89-94. doi: 10.1139/z88-012

Krause, D. J., Goebel, M. E., Marshall, G. J., and Abernathy, K. (2015). Novel foraging strategies observed in a growing leopard seal (Hydrurga leptonyx) population at Livingston Island, Antarctic Peninsula. Animal Biotelemetry 3:24. doi: 10.1186/s40317-015-0059-2

Krause, D. J., Goebel, M. E., Marshall, G. J., and Abernathy, K. (2016). Summer diving and haul-out behavior of leopard seals (Hydrurga leptonyx) near mesopredator breeding colonies at Livingston Island, Antarctic Peninsula. Mar. Mammal Sci. 32, 839-867. doi: 10.1111/mms.12309

Kuhn, C. E., Crocker, D. E., Tremblay, Y., and Costa, D. P. (2009). Time to eat: measurements of feeding behaviour in a large marine predator, the northern elephant seal Mirounga angustirostris. J. Ani. Eco. 78, 513-523. doi: $10.1111 /$ j.1365-2656.2008.01509.x

Kuhn, C. E., McDonald, B. I., Shaffer, S. A., Barnes, J., Crocker, D. E., Burns, J., et al. (2006). Diving physiology and winter foraging behavior of a juvenile leopard seal (Hydrurga leptonyx). Polar Biol. 29, 303-307. doi: 10.1007/s00300-005-0053-x

Labrousse, S., Vacquié-Garcia, J., Heerah, K., Guinet, C., Sallée, J. B., Authier, M., et al. (2015). Winter use of sea ice and ocean water mass habitat by southern elephant seals: the length and breadth of the mystery. Prog. Oceanogr. 137, 52-68. doi: 10.1016/j.pocean.2015.05.023

Langrock, R., King, R., Matthiopoulos, J., Thomas, L., Fortin, D., and Morales, J. M. (2012). Flexible and practical modeling of animal telemetry data: hidden Markov models and extensions. Ecology 93, 2336-2342. doi: 10.1890/11-2241.1

Larsen, J. N., Anisimov, O. A., Constable, A., Hollowed, A. B., Maynard, N., Prestrud, P., et al. (2014). "Polar regions," in Climate Change 2014: Impacts, Adaptation, and Vulnerability, (Cambridge: Cambridge University Press), 1567-1612.

Le Boeuf, B. J., and Crocker, D. E. (2005). Ocean climate and seal condition. BMC Biol. 3:9. doi: 10.1186/1741-7007-3-9

Le Bras, Y., Jouma'a, J., Picard, B., and Guinet, C. (2016). How elephant seals (Mirounga leonina) adjust their fine scale horizontal movement and diving behaviour in relation to prey encounter rate. PLOS ONE 11:e0167226. doi: 10.1371/journal.pone. 0167226
Le Vaillant, M., Le Bohec, C., Prud'Homme, O., Wienecke, B., Le Maho, Y., Kato, A., et al. (2013). How age and sex drive the foraging behaviour in the king penguin. Mar. Biol. 160, 1147-1156.

Le Vaillant, M., Wilson, R. P., Kato, A., Saraux, C., Hanuise, N., Prud'Homme, O., et al. (2012). King penguins adjust their diving behaviour with age. J. Exp. Biol. $215,3685-3692$.

Lea, M. A., and Dubroca, L. (2003). Fine-scale linkages between the diving behaviour of Antarctic fur seals and oceanographic features in the southern Indian Ocean. ICES J. Mar. Sci. 60, 990-1002. doi: 10.1016/S1054-3139(03)00101-2

Lea, M. A., Guinet, C., Cherel, Y., Duhamel, G., Dubroca, L., Pruvost, P., et al. (2006). Impacts of climatic anomalies on provisioning strategies of a Southern Ocean predator. Mar. Ecol. Prog. Ser. 310, 77-94. doi: 10.3354/meps310077

Lea, M. A., Hindell, M. A., Guinet, C., and Goldsworthy, S. D. (2002). Variability in the diving activity of Antarctic fur seals, Arctocephalus gazella, at Iles Kerguelen. Polar Biol. 25, 269-279. doi: 10.1007/s00300-001-0339-6

Lea, S. E., Daley, C., Boddington, P. J., and Morison, V. (1996). Diving patterns in shags and cormorants (Phalacrocorax): tests of an optimal breathing model. Ibis 138, 391-398. doi: 10.1111/j.1474-919X.1996.tb08056.x

Lee, W. Y., Kokubun, N., Jung, J.-W., Chung, H., and Kim, J.-H. (2015). Diel diving behavior of breeding gentoo penguins on King George Island in Antarctica. Animal Cells Syst. 19, 274-281. doi: 10.1080/19768354.2015.1074107

Lenfant, C., Kooyman, G. L., Elsner, R., and Drabek, C. M. (1969). Respiratory function of blood of the Adélie penguin Pygoscelis adeliae. Am. J. Physiol. 6, 1598-1600. doi: 10.1152/ajplegacy.1969.216.6.1598

Ludynia, K., Dehnhard, N., Poisbleau, M., Demongin, L., Masello, J. F., and Quillfeldt, P. (2012). Evaluating the impact of handling and logger attachment on foraging parameters and physiology in southern rockhopper penguins. PLoS ONE 7:e50429. doi: 10.1371/journal.pone.0050429

Luque, S. P., Arnould, J. P. Y., and Guinet, C. (2008). Temporal structure of diving behaviour in sympatric Antarctic and sub-Antarctic fur seals. Mar. Ecol. Prog. Ser. 372, 277-287. doi: 10.3354/meps07689

Luque, S. P., Arnould, J. P. Y., Miller, E. H., Cherel, Y., and Guinet, C. (2007a). Foraging behaviour of sympatric Antarctic and sub-Antarctic fur seals: does their contrasting duration of lactation make a difference? Mar. Biol. 152, 213-224. doi: 10.1007/s00227-007-0677-1

Luque, S. P., and Guinet, C. (2007b). A maximum likelihood approach for identifying dive bouts improves accuracy, precision and objectivity. Behaviour 144, 1315-1332. doi: 10.1163/156853907782418213

Madden, K. M., Fuiman, L. A., Williams, T. M., and Davis, R. W. (2015). Weddell seal foraging dives: comparison of free-ranging and isolated-hole paradigms. Antarct. Sci. 27, 57-68. doi: 10.1017/S0954102014000297

Malpress, V., Bestley, S., Corney, S., Welsford, D., Labrousse, S., Sumner, M., et al. (2017). Bio-physical characterisation of polynyas as a key foraging habitat for juvenile male southern elephant seals (Mirounga leonina) in Prydz Bay, East Antarctica. PLoS ONE 12:e0184536. doi: 10.1371/journal.pone. 0184536

Mate, B., Mesecar, R., and Lagerquist, B. (2007). The evolution of satellitemonitored radio tags for large whales: one laboratory's experience. Deep-Sea Res. Pt II Top. Stud. Oceanogr. 54, 224-247.

McDonald, B. I., and Ponganis, P. J. (2012). Lung collapse in the diving sea lion: hold the nitrogen and save the oxygen. Biol. Lett. 8, 1047-1049. doi: $10.1098 / \mathrm{rsbl} .2012 .0743$

McDonald, B. I., and Ponganis, P. J. (2013). Insights from venous oxygen profiles: oxygen utilization and management in diving California sea lions. J. Exp. Bio. 216, 3332-3341. doi: 10.1242/jeb.085985

McInnes, J. C., Alderman, R., Deagle, B. E., Lea, M. A., Raymond, B., and Jarman, S. N. (2017). Optimised scat collection protocols for dietary DNA metabarcoding in vertebrates. Methods Ecol. Evol. 8, 192-202. doi: 10.1111/2041-210X.12677

McInnes, J. C., Raymond, B., Phillips, R. A., Jarman, S. N., Lea, M. A., and Alderman, R. (2016). A review of methods used to analyse albatross dietsassessing priorities across their range. ICES J. Mar. Sci. 73, 2125-2137. doi: 10.1093/icesjms/fsw105

McIntyre, T. (2014). Trends in tagging of marine mammals: a review of marine mammal biologging studies. Afr. J. Mar. Sci. 36, 409-422. doi: 10.2989/1814232X.2014.976655

McIntyre, T., De Bruyn, P. J. N., Ansorge, I. J., Bester, M. N., Bornemann, H., and Plötz, J. (2010). A lifetime at depth: vertical distribution of 
southern elephant seals in the water column. Polar Biol. 33, 1037-1048. doi: 10.1007/s00300-010-0782-3

McMahon, C. R., Harcourt, R. G., Burton, H. R., Daniel, O., and Hindell, M. A. (2017). Seal mothers expend more on offspring under favourable conditions and less when resources are limited. J. Anim. Ecol. 86, 359-370. doi: 10.1111/1365-2656.12611

Meir, J. U., Champagne, C. D., Costa, D. P., Williams, C. L., and Ponganis, P. J. (2009). Extreme hypoxemic tolerance and blood oxygen depletion in diving elephant seals. Am. J. Physiol. Regul. Integr. Comp. Physiol. 297, R927-R939. doi: 10.1152/ajpregu.00247.2009

Meir, J. U., Stockard, T. K., Williams, C. L., Ponganis, K. V., and Ponganis, P. J. (2008). Heart rate regulation and extreme bradycardia in diving emperor penguins. J. Exp. Biol. 211, 1169-1179. doi: 10.1242/jeb.013235

Michelot, T., Langrock, R., and Patterson, T. A. (2016). moveHMM: an $\mathrm{R}$ package for the statistical modelling of animal movement data using hidden Markov models. M. Eco. Evol. 7, 1308-1315. doi: 10.1111/2041-210X. 12578

Miller, P. J., Biuw, M., Watanabe, Y. Y., Thompson, D., and Fedak, M. A. (2012). Sink fast and swim harder! Round-trip cost-of-transport for buoyant divers. J. Exp. Biol. 215, 3622-3630. doi: 10.1242/jeb.070128

Mori, Y. (1998). Optimal choice of foraging depth in divers. J. Zool. 245, 279-283. doi: 10.1111/j.1469-7998.1998.tb00102.x

Mori, Y. (2002). Optimal diving behaviour for foraging in relation to body size. J. Evol. Biol. 15, 269-276. doi: 10.1046/j.1420-9101.2002.00382.x

Mori, Y. (2012). Differences in diving behaviour optimality may cause differences in reproductive success in chinstrap penguins: a cases study. Open Ornithol. J. 5, 57-60. doi: 10.2174/1874453201205010057

Mori, Y., and Boyd, I. L. (2004). The behavioral basis for nonlinear functional responses and optimal foraging in Antarctic fur seals. Ecology 85, 398-410. doi: 10.1890/03-4005

Mori, Y., Watanabe, Y., Mitani, Y., Sato, K., Cameron, M. F., and Naito, Y. (2005). A comparison of prey richness estimates for Weddell seals using diving profiles and image data. Mar. Ecol. Prog. Ser. 295, 257-263. doi: 10.3354/meps295257

Nagy, K. A., Kooyman, G. L., and Ponganis, P. J. (2001). Energetic cost of foraging in free-diving emperor penguins. Physiol. Biochem. Zool. 74, 541-547. doi: $10.1086 / 322165$

Naito, Y. (2010). Historical perspectives: What is "Bio-Logging"? Aquat. Mamm. 36, 307-322. doi: 10.1578/AM.36.3.2010.307

Naito, Y., Bornemann, H., Takahashi, A., McIntyre, T., and Plötz, J. (2010). Finescale feeding behavior of Weddell seals revealed by a mandible accelerometer. Polar Sci. 4, 309-316. doi: 10.1016/j.polar.2010.05.009

Naito, Y., Costa, D. P., Adachi, T., Robinson, P. W., Fowler, M., and Takahashi, A. (2013). Unravelling the mysteries of a mesopelagic diet: a large apex predator specializes on small prey. Funct. Ecol. 27, 710-717. doi: $10.1111 / 1365-2435.12083$

Navarro, J., Votier, S. C., and Phillips, R. A. (2014). Diving capabilities of diving petrels. Polar Biol. 37, 897-901. doi: 10.1007/s00300-014-1483-0

New, L. F., Clark, J. S., Costa, D. P., Fleishman, E., Hindell, M. A., Klanjscek, T., et al. (2014). Using short-term measures of behaviour to estimate longterm fitness of southern elephant seals. Mar. Ecol. Prog. Ser. 496, 99-108. doi: 10.3354/meps10547

Nordøy, E. S., and Blix, A. S. (2009). Movements and dive behaviour of two leopard seals (Hydrurga leptonyx) off Queen Maud Land, Antarctica. Polar Biol. 32, 263-270. doi: 10.1007/s00300-008-0527-8

Noren, S. R., and Williams, T. M. (2000). Body size and skeletal muscle myoglobin of cetaceans: adaptations for maximising dive duration. Comp. Biochem. Physiol. Part A Mol. Integr. Physiol. 126, 181-191. doi: 10.1016/S1095-6433(00)00182-3

Oliver, M. J., Irwin, A., Moline, M. A., Fraser, W., Patterson, D., Schofield, O., et al. (2013). Adélie penguin foraging location predicted by tidal regime switching. PLoS ONE 8:e55163. doi: 10.1371/journal.pone.0055163

O’Toole, M. D., Lea, M. A., Guinet, C., and Hindell, M. A. (2014). Estimating transseasonal variability in water column biomass for a highly migratory, deep diving predator. PLoS ONE 9:e113171. doi: 10.1371/journal.pone.0113171

Patterson, T. A., McConnell, B. J., Fedak, M. A., Bravington, M. V., and Hindell, M. A. (2010). Using GPS data to evaluate the accuracy of state-space methods for correction of Argos satellite telemetry error. Ecology 91, 273-285. doi: $10.1890 / 08-1480.1$
Phalan, B., Phillips, R. A., Silk, J. R. D., Afanasyev, V., Fukuda, A., Fox, J., et al. (2007). Foraging behaviour of four albatross species by night and day. Mar. Ecol. Prog. Ser. 340, 271-286. doi: 10.3354/meps340271

Phillips, R. A., Croxall, J. P., Silk, J. R. D., and Briggs, D. R. (2007). Foraging ecology of albatrosses and petrels from South Georgia: two decades of insights from tracking technologies. Aquat. Conserv. 17, S6-S21. doi: 10.1002/aqc.906

Phillips, R. A., Silk, J. R. D., and Croxall, J. P. (2005). Foraging and provisioning strategies of the light-mantled sooty albatross at South Georgia: competition and co-existence with sympatric pelagic predators. Mar. Ecol. Prog. Ser. 285, 259-270. doi: 10.3354/meps285259

Photopoulou, T., Lovell, P., Fedak, M. A., Thomas, L., and Matthiopoulos, J. (2015). Efficient abstracting of dive profiles using a broken-stick model. M. Ecol. Evol. 6, 2782-2288. doi: 10.1111/2041-210X.12328

Pierce, G. J., and Boyle, P. R. (1991). A review of methods for diet analysis in piscivorous marine mammals. Oceanogr. Mar. Biol. 29, 409-486.

Pinheiro, J., Bates, D., DebRoy, S., Sarkar, D., and R Core Team (2018)._nlme: Linear and Nonlinear Mixed Effects Models_. R package Version 3.1-137.

Ponganis, P., Meir, J., and Williams, C. (2010a). Oxygen store depletion and the aerobic dive limit in emperor penguins. Aquat. Biol. 8, 237-245. doi: $10.3354 / \mathrm{ab} 00216$

Ponganis, P. J. (2011). "Diving mammals," in Comprehensive Physiology, ed R. Terjung (Hoboken, NJ: Wiley), 517-535. doi: 10.1002/cphy.c091003

Ponganis, P. J., Costello, M. L., Starke, L. N., Mathieu-Costello, O., and Kooyman, G. L. (1997b). Structural and biochemical characteristics of locomotory muscles of emperor penguins, Aptenodytes forsteri. Respir. Physiol. 109, 73-80. doi: 10.1016/S0034-5687(97)84031-5

Ponganis, P. J., and Kooyman, G. L. (2000). Diving physiology of birds: a history of studies on polar species. Comp. Biochem. Physiol. Part A Mol. Integr. Physiol. 126, 143-151. doi: 10.1016/S1095-6433(00)00208-7

Ponganis, P. J., Kooyman, G. L., and Castellini, M. A. (1993). Determinants of the aerobic dive limit of Weddell seals: analysis of diving metabolic rates, postdive end tidal Po2's, and blood and muscle oxygen stores. Physiol. Zool. 66, 732-749.

Ponganis, P. J., Kooyman, G. L., Starke, L. N., Kooyman, C. A., and Kooyman, T. G. (1997a). Post-dive blood lactate concentrations in emperor penguins, Aptenodytes forsteri. J. Exp. Biol. 11, 1623-1626.

Ponganis, P. J., Meir, J. U., and Williams, C. L. (2011). In pursuit of Irving and Scholander: a review of oxygen store management in seals and penguins. J. Exp. Bio. 214, 3325-3339. doi: 10.1242/jeb.031252

Ponganis, P. J., Stockard, T. K., Meir, J. U., Williams, C. L., Ponganis, K. V., and Howard, R. (2009). $\mathrm{O}_{2}$ store management in diving emperor penguins. J. Exp. Biol. 212, 217-224. doi: 10.1242/jeb.026096

Ponganis, P. J., Stockard, T. K., Meir, J. U., Williams, C. L., Ponganis, K. V., Van Dam, R. P., et al. (2007). Returning on empty: extreme blood O2 depletion underlies dive capacity of emperor penguins. J. Exp. Biol. 210, 4279-4285. doi: $10.1242 /$ jeb.011221

Ponganis, P. J., Welch, T. J., Welch, L. S., and Stockard, T. K. (2010b). Myoglobin production in emperor penguins. J. Experim. Bio. 213, 1901-1906. doi: $10.1242 /$ jeb.042093

Prince, P. A., Huin, N., and Weimerskirch, H. (1994). Diving depths of albatrosses. Antarctic Sci. 6, 353-354. doi: 10.1017/S0954102094000532

Pütz, K., Rey, A. R., Huin, N., Schiavini, A., Pütz, A., and Lüthi, B. H. (2006). Diving characteristics of southern rockhopper penguins (Eudyptes c. chrysocome) in the southwest Atlantic. Mar. Biol. 149, 125-137. doi: 10.1007/s00227-005-0179-y

Quick, N. J., Isojunno, S., Sadykova, D., Bowers, M., Nowacek, D. P., and Read, A. J. (2017). Hidden Markov models reveal complexity in the diving behaviour of short-finned pilot whales. Sci. Rep. 7:45765. doi: 10.1038/srep45765

Quintana, F., Wilson, R. P., and Yorio, P. (2007). Dive depth and plumage air in wettable birds: the extraordinary case of the imperial cormorant. Mar. Ecol. Prog. Ser. 334, 299-310. doi: 10.3354/meps334299

Raya Rey, A., Pütz, K., Luna-Jorquera, G., Lüthi, B., and Schiavini, A. (2009). Diving patterns of breeding female rockhopper penguins (Eudyptes chrysocome): Noir Island, Chile. Polar Biol. 32, 561-568. doi: 10.1007/s00300-008-0550-9

Raymond, B., Lea, M. A., Patterson, T., Andrews-Goff, V., and Sharples, R., Charrassin, J.-B., et al. (2015). Important marine habitat off east Antarctica revealed by two decades of multi-species predator tracking. Ecography 38, 121-129. doi: 10.1111/ecog.01021 
Reisinger, R. R., Keith, M., Andrews, R. D., and de Bruyn, P. J. N. (2015). Movement and diving of killer whales (Orcinus orca) at a Southern Ocean archipelago. J. Exp. Mar. Biol. Ecol. 473, 90-102. doi: 10.1016/j.jembe.2015.08.008

Reisinger, R. R., Raymond, B., Hindell, M. A., Bester, M. N., Crawford, R. J. M., Davies, D., et al. (2018). Habitat modelling of tracking data from multiple marine predators identifies important areas in the Southern Indian Ocean. Divers Distrib. 24, 535-550. doi: 10.1111/ddi.12702

Richard, G., Vacquié-Garcia, J., Jouma’a, J., Picard, B., Génin, A, Arnould, J. P. Y., et al. (2014). Variation in body condition during the post-moult foraging trip of southern elephant seals and its consequences on diving behaviour. J. Exp. Biol. 217, 2609-2619.

Ridgway, S. H., Scronce, B. L., and Kanwisher, J. (1969). Respiration and deep diving in the bottlenose porpoise. Science 166, 1651-1654. doi: 10.1126/science.166.3913.1651

Robinson, P. W., Simmons, S. E., Crocker, D. E., and Costa, D. P. (2010). Measurements of foraging success in a highly pelagic marine predator, the northern elephant seal. J. Anim. Ecol. 79, 1146-1156. doi: 10.1111/j.1365-2656.2010.01735.x

Robison, B. H. (2003). What drives the diel vertical migrations of Antarctic midwater fish? J. Mar. Biol. Assoc. 83, 639-642. doi: 10.1017/S0025315403007586h

Rollinson, D. P., Dilley, B. J., and Ryan, P. G. (2014). Diving behaviour of whitechinned petrels and its relevance for mitigating longline bycatch. Polar Biol. 9, 1301-1308. doi: 10.1007/s00300-014-1521-y

Ronconi, R. A., Ryan, P. G., and Ropert-Coudert, Y. (2010). Diving of great shearwaters (Puffinus gravis) in cold and warm water regions of the South Atlantic Ocean. PLoS ONE 5:e15508. doi: 10.1371/journal.pone.0015508

Ropert-Coudert, Y., Hindell, M. A., Phillips, R. A., Charrassin, J. B., Trudelle, L., and Raymond, B. (2014). "Biogeographic patterns of birds and mammals", in Biogeographic Atlas of the Southern Ocean (Cambridge: Scientific Committee on Antarctic Research), 1-10.

Ropert-Coudert, Y., Sato, K., Kato, A., Charrassin, J. B., Bost, C. A., Maho, Y. L., et al. (2000). Preliminary investigations of prey pursuit and capture by king penguins at sea. Polar Biosci. 13, 101-112.

Rosciano, N. G., Polito, M. J., and Raya Rey, A. (2016). Do penguins share? Evidence of foraging niche segregation between but not within two sympatric, central-place foragers. Mar. Ecol. Prog. Ser. 548, 249-262. doi: $10.3354 /$ meps 11689

Russell, D. J., McClintock, B. T., Matthiopoulos, J., Thompson, P. M., Thompson, D., Hammond, P. S., et al. (2015). Intrinsic and extrinsic drivers of activity budgets in sympatric grey and harbour seals. Oikos 124, 1462-1472. doi: 10.1111/oik.01810

Schick, R. S., New, L. F., Thomas, L., Costa, D. P., Hindell, M. A., McMahon, C. R., et al. (2013). Estimating resource acquisition and at-sea body condition of a marine predator. J. Anim. Ecol. 82, 1300-1315. doi: 10.1111/1365-2656.12102

Schreer, J. F., Kovacs, K. M., and O'Hara Hines, R. J. (2001). Comparative diving patterns of pinnipeds and seabirds. Ecol. Monogr. 71, 137-162. doi: 10. 1890/0012-9615(2001)071[0137:CDPOPA]2.0.CO;2

Schulz, T. M., and Bowen, W. D. (2004). Pinniped lactation strategies: evaluation of data on maternal and offspring life history traits. Mar. Mammal. Sci. 20, 86-114. doi: 10.1111/j.1748-7692.2004.tb01142.x

Shiomi, K., Sato, K., and Ponganis, P. J. (2012). Point of no return in diving emperor penguins: is the timing of the decision to return limited by the number of strokes? J. Exp. Bio. 215, 135-140. doi: 10.1242/jeb.064568

Siesj,ö, B. K. (1988). Acidosis and ischemic brain damage. Neurochem. Pathol. 9, 31-88.

Simeone, A., and Wilson, R. P. (2003). In-depth studies of Magellanic penguin (Spheniscus magellanicus) foraging: can we estimate prey consumption by perturbations in the dive profile? Mar. Biol. 143, 825-831. doi: 10.1007/s00227-003-1114-8

Smith, R. C., Fraser, W. R., and Stammerjohn, S. E. (2003). Climate Variability and Ecological Response of the Marine Ecosystem in the Western Antarctic Peninsula (WAP) region. New York, NY: Oxford University Press.

Sparling, C. E., Georges, J. Y., Gallon, S. L., Fedak, M., and Thompson, D. (2007). How long does a dive last? Foraging decisions by breath-hold divers in a patchy environment: a test of a simple model. Anim. Behav. 74, 207-218. doi: 10.1016/j.anbehav.2006.06.022
Staniland, I. J., Gales, N., Warren, N. L., Robinson, S. L., Goldsworthy, S. D., and Casper, R. M. (2010). Geographical variation in the behaviour of a central place forager: Antarctic fur seals foraging in contrasting environments. Mar. Biol. 157, 2383-2396. doi: 10.1007/s00227-010-1503-8

Stephens, D. W., and Krebs, J. R. (1986). Foraging Theory. Princeton, NJ: Princeton University Press.

Sue-Anne, B. (2012). Feeding Ecology of White-Chinned Petrels: Diet and Their Diving Patterns Around South Georgia. Doctoral dissertation, Universidade de Coimbra, Portugal.

Takahashi, A., Dunn, M. J., Trathan, P. N., Sato, K., Naito, Y., and Croxall, J. P. (2003). Foraging strategies of chinstrap penguins at Signy Island, Antarctica: importance of benthic feeding on Antarctic krill. Mar. Ecol. Prog. Ser. 250, 279-289. doi: 10.3354/meps250279

Takahashi, A., Kokubun, N., Mori, Y., and Shin, H. C. (2008). Krill-feeding behaviour of gentoo penguins as shown by animal-borne camera loggers. Polar Biol. 31, 1291-1294. doi: 10.1007/s00300-008-0502-4

Taylor, C. R., Karas, R. H., Weibel, E. R., and Hoppeler, H. (1987). Adaptive variation in the mammalian respiratory system in relation to energetic demand: II. Reaching the limits to oxygen flow. Resp. Physiol. 69, 7-26. doi: 10.1016/0034-5687(87)90098-3

Thiebot, J. B., Cherel, Y., Trathan, P. N., and Bost, C. A. (2012). Coexistence of oceanic predators on wintering areas explained by population-scale foraging segregation in space or time. Ecology 93, 122-130. doi: 10.1890/11-0385.1

Thompson, D., and Fedak, M. A. (2001). How long should a dive last? A simple model of foraging decisions by breath-hold divers in a patchy environment. Anim. Behav. 61, 287-296. doi: 10.1006/anbe.2000.1539

Thums, M., Bradshaw, C. J., Sumner, M. D., Horsburgh, J. M., and Hindell, M. A. (2013). Depletion of deep marine food patches forces divers to give up early. J. Anim. Ecol. 82, 72-83. doi: 10.1111/j.1365-2656.2012.02021.x

Thums, M., Bradshaw, C. J. A., and Hindell, M. A. (2008). A validated approach for supervised dive classification in diving vertebrates. J. Exp. Mar. Biol. Ecol. 363, 75-83. doi: 10.1016/j.jembe.2008.06.024

Trathan, P. N., Croxall, J. P., and Murphy, E. J. (1996). Dynamics of Antarctic penguin populations in relation to inter-annual variability in sea ice distribution. Polar Biol. 16, 321-330. doi: 10.1007/BF02342178

Trathan, P. N., and Hill, S. L. (2016). "The importance of krill predation in the Southern Ocean," in Biology and Ecology of Antarctic Krill, ed V. Siegel (Basel: Springer), 321-350. doi: 10.1007/978-3-319-29279-3_9

Tremblay, Y., and Cherel, Y. (2005). Spatial and temporal variation in the provisioning behaviour of female rockhopper penguins Eudyptes chrysocome filholi. J. Avian Biol. 36, 135-145. doi: 10.1111/j.0908-8857.2005.03309.x

Tyack, P. L., Johnson, M., Soto, N. .A., Sturlese, A., and Madsen, P. T. (2006). Extreme diving of beaked whales. J. Exp. Biol. 209, 4238-4253. doi: $10.1242 /$ jeb.02505

Tyson, R. B., Friedlaender, A. S., and Nowacek, D. P. (2016). Does optimal foraging theory predict the foraging performance of a large air-breathing marine predator? Animal Behav. 116, 223-235. doi: 10.1016/j.anbehav.2016.03.034

Vacquié-Garcia, J., Guinet, C., Dragon, A. C., Viviant, M., El Ksabi, N., and Bailleul, F. (2015). Predicting prey capture rates of southern elephant seals from track and dive parameters. Mar. Eco. Prog. Ser. 541, 265-277. doi: 10.3354/meps11511

Verrier, D., Guinet, C., Authier, M., Tremblay, Y., Shaffer, S., Costa, D. P., et al. (2011). The ontogeny of diving abilities in sub-Antarctic fur seal pups: developmental trade-off in response to extreme fasting? Funct. Ecol. 25, 818-828. doi: 10.1111/j.1365-2435.2011.01846.x

Viviant, M., Jeanniard-du-Dot, T., Monestiez, P., Authier, M., and Guinet, C. (2016). Bottom time does not always predict prey encounter rate in Antarctic fur seals. Funct. Ecol. 30, 1834-1844. doi: 10.1111/1365-2435.12675

Viviant, M., Monestiez, P., and Guinet, C. (2014). Can we predict foraging success in a marine predator from dive patterns only? Validation with prey capture attempt data. PLoS ONE 9:e88503. doi: 10.1371/journal.pone.0088503

Viviant, M., Trites, A. W., Rosen, D. A., Monestiez, P., and Guinet, C. (2010). Prey capture attempts can be detected in Steller sea lions and other marine predators using accelerometers. Polar Biol. 33, 713-719. doi: 10.1007/s00300-009-0750-y

Walters, A., Lea, M. A., van den Hoff, J., Field, I. C., Virtue, P., Sokolov, S., et al. (2014). Spatially explicit estimates of prey consumption reveal a new krill predator in the Southern Ocean. PLoS ONE 9:e86452. doi: 10.1371/journal.pone.0086452 
Watanabe, Y. Y., Ito, M., and Takahashi, A. (2014). Testing optimal foraging theory in a penguin-krill system. Proc. R. Soc. Lond. B. Biol. Sci. 281:20132376. doi: $10.1098 / \mathrm{rspb} .2013 .2376$

Watanabe, Y. Y., and Takahashi, A. (2013). Linking animal-borne video to accelerometers reveals prey capture variability. Proc. Natl. Acad. Sci. U.S.A. 110, 2199-2204. doi: 10.1073/pnas.1216244110

Watanabe, Y. Y., Takahashi, A., Sato, K., Viviant, M., and Bost, C.-A. (2011). Poor flight performance in deep-diving cormorants. J. Exp. Biol. 214, 412-421. doi: 10.1242/jeb.050161

Watanuki, Y., Takahashi, A., and Sato, K. (2010). Individual variation of foraging behavior and food provisioning in Adélie penguins (Pygoscelis adeliae) in a Fast-Sea-Ice Area. Auk 127, 523-531. doi: 10.1525/auk.2010.09088

Webb, P. M., Crocker, D. E., Blackwell, S. B., Costa, D. P., and Le Boeuf, B. J. (1998). Effects of buoyancy on the diving behavior of northern elephant seals. J. Exp. Biol. 201, 2349-2358.

Weber, R. E., Hemmingsen, E. A., and Johansen, K. (1974). Functional nand biochemical studies of penguin myoglobins. Comp. Biochem. Physiol. 49, 197-214.

Weinstein, B. G., and Friedlaender, A. S. (2017). Dynamic foraging of a top predator in a seasonal polar marine environment. Oecologia 185, 427-435. doi: 10.1007/s00442-017-3949-6

Whitehead, T. O., Kato, A., Ropert-Coudert, Y., and Ryan, P. G. (2016). Habitat use and diving behaviour of macaroni Eudyptes chrysolophus and eastern rockhopper E. chrysocome filholi penguins during the critical pre-moult period. Mar. Bio. 163:19. doi: 10.1007/s00227-015-2794-6

Wienecke, B., Robertson, G., Kirkwood, R., and Lawton, K. (2007). Extreme dives by free-ranging emperor penguins. Polar Biol. 30, 133-142. doi: 10.1007/s00300-006-0168-8

Wildenthal, K., Mierzwiak, D. S., Myers, R. W., and Mitchell, J. H. (1968). Effects of acute lactic acidosis on left ventricular performance. Am. J. Physiol. 214, 1352-1359. doi: 10.1152/ajplegacy.1968.214.6.1352

Williams, C. L., Sato, K., Shiomi, K., and Ponganis, P. J. (2012). Muscle energy stores and stroke rates of emperor penguins: implications for muscle metabolism and dive performance. Physio. Bioch. Zoo. 85, 120-133. doi: $10.1086 / 664698$

Williams, T. D., Briggs, D. R., Croxall, J. P., Naito, Y., and Kato, A. (1992). Diving pattern and performance in relation to foraging ecology in the gentoo penguin, Pygoscelis papua. J. Zool. 227, 211-230. doi: 10.1111/j.1469-7998.1992.tb04818.x

Williams, T. M., Davis, R. W., Fuiman, L. A., Francis, J., Le Le Boeuf, B. J., Horning, M., et al. (2000). Sink or swim: strategies for cost-efficient diving by marine mammals. Science 288, 133-136. doi: 10.1126/science.288.5463.133

Williams, T. M., Kendall, T. L., Richter, B. P., Ribeiro-French, C. R., John, J. S., Odell, K. L., et al. (2017). Swimming and diving energetics in dolphins: a strokeby-stroke analysis for predicting the cost of flight responses in wild odontocetes. J. Exp. Biol. 220, 1135-1145. doi: 10.1242/jeb.154245
Wilson, R. P., Cooper, J., and Plötz, J. (1992). Can we determine when marine endotherms feed? A case study with seabirds. J. Exp. Biol. 167, 267-275.

Wilson, R. P., Shepard, E. L. C., Laich, A. G., Frere, E., and Quintana, F. (2010). Pedalling downhill and freewheeling up; a penguin perspective on foraging. Aquat. Biol. 8, 193-202. doi: 10.3354/ab00230

Wilson, R. P., White, C. R., Quintana, F., Halsey, L. G., Liebsch, N., Martin, G. R., et al. (2006). Moving towards acceleration for estimates of activity-specific metabolic rate in free-living animals: the case of the cormorant. J. Anim. Ecol. 75, 1081-1090. doi: 10.1111/j.1365-2656.2006.01127.x

Winship, A. J., Jorgensen, S. J., Shaffer, S. A., Jonsen, I. D., Robinson, P. W., Costa, D. P., et al. (2012). State-space framework for estimating measurement error from double-tagging telemetry experiments. Methods Ecol. Evol. 3, 291-302. doi: 10.1111/j.2041-210X.2011.00161.x

Woehler, E. J., and Croxall, J. P. (1997). The status and trends of Antarctic and sub-Antarctic seabirds. Mar. Ornithol. 25, 43-66.

Wood, S., and Scheipl, F. (2017). Gamm4: Generalized Additive Mixed Models using 'mgcv' and 'me4'. R Package Version 0.2-5.

Wright, A. K., Ponganis, K. V., McDonald, B. I., and Ponganis, P. J. (2014). Heart rates of emperor penguins diving at sea: implications for oxygen store management. Mar. Ecol. Progr. Ser. 496, 85-98. doi: 10.3354/meps 10592

Zapol, W. M. (1996). "Diving physiology of the Weddell seal," in Handbook of Physiology, Section 4: Environmental Physiology, Vol. II, eds M. J. Fregly and C. M. Blatteis (Oxford: Oxford University Press), 1049-1056.

Zimmer, I., Wilson, R., Gilbert, C., Beaulieu, M., Ancel, A., and Plötz, J. (2008a). Foraging movements of emperor penguins at Pointe Géologie, Antarctica. Polar Biol. 31, 229-243. doi: 10.1007/s00300-007-0352-5

Zimmer, I., Wilson, R. P., Beaulieu, M., Ancel, A., and Plötz, J. (2008b). Seeing the light: depth and time restrictions in the foraging capacity of emperor penguins at pointe geologie, Antarctica. Aquat. Biol. 3, 217-226. doi: 10.3354/ab 00082

Conflict of Interest Statement: The authors declare that the research was conducted in the absence of any commercial or financial relationships that could be construed as a potential conflict of interest.

The reviewer TP declared a past co-authorship with one of the authors SB to the handling editor.

Copyright (c) 2018 Roncon, Bestley, McMahon, Wienecke and Hindell. This is an open-access article distributed under the terms of the Creative Commons Attribution License (CC BY). The use, distribution or reproduction in other forums is permitted, provided the original author(s) and the copyright owner(s) are credited and that the original publication in this journal is cited, in accordance with accepted academic practice. No use, distribution or reproduction is permitted which does not comply with these terms. 